\title{
Asset Market Participation and Portfolio Choice over the Life-Cycle
}

\author{
ANDREAS FAGERENG, CHARLES GOTTLIEB, and LUIGI GUISO*
}

\begin{abstract}
Using error-free data on life-cycle portfolio allocations of a large sample of Norwegian households, we document a double adjustment as households age: a rebalancing of the portfolio composition away from stocks as they approach retirement and stock market exit after retirement. When structurally estimating an extended life-cycle model, the parameter combination that best fits the data is one with a relatively large risk aversion, a small per-period participation cost, and a yearly probability of a large stock market loss in line with the frequency of stock market crashes in Norway.
\end{abstract}

Keywords: portfolio choice, portfolio rebalancing, asset market participation, life-cycle model. JEL classification: G11, D14, D91.

\footnotetext{
${ }^{*}$ Andreas Fagereng is with Statistics Norway. Charles Gottlieb is with the University of St. Gallen, SEW, and CFM. Luigi Guiso is with the Einaudi Institute for Economics and Finance and CEPR. We would like to thank the Editor (Kenneth Singleton), the Associate Editor, and two anonymous referees for their insightful comments. We are particularly thankful to Facundo Piguillem. Also we thank Árpád Ábrahám, Jerôme Adda, Francisco Gomes, Maria Gustafsson, Elin Halvorsen, Jonathan Heathcote, Dirk Krueger, Kim Peijnenburg, Arvid Raknerud, and Marno Verbeek for helpful discussions and suggestions. We are grateful to João Cocco for making the code of his life-cycle model available to us, and to Bernt Arne Ødegård for providing us with ISIN codes and end-of-period prices of the Oslo Stock Exchange. We thank seminar participants at the University of Frankfurt, University of St. Gallen, University of Cambridge, EIEF, University of Oxford, European University Institute, European Central Bank, Statistics Norway, Norges Bank, NHH Bergen, ESEM 2011, SED 2012, IIPF 2013, EALE 2014, and the 2015 WU Gutmann Symposium. We are grateful to NETSPAR for financial support. Andreas Fagereng thanks the Norwegian Research Council for support through grants \#184563 and \#236921. Charles Gottlieb gratefully acknowledges research support from Research Center SAFE, funded by the State of Hessen initiative for research LOEWE. No party had the right to review the article prior to its circulation. We (the authors) did not receive any funding from interested parties, and we also have no relevant potential conflicts of interest with this article.
} 
This paper reexamines empirically the life-cycle behavior of investors' portfolios, establishing novel features of the joint profiles of investors' participation in the stock market and the portfolio share invested in stocks. We estimate the parameters of a standard life-cycle portfolio model with uninsurable labor income, extended to incorporate costly participation and a small probability of a stock market crash, and show that it can capture these features.

Inspired by empirical findings from novel microeconomic data on households' portfolios, several recent studies provide new contributions to the literature on life-cycle portfolio choice of individual investors building on the seminal contributions of Mossin (1968), Samuelson (1969), and Merton (1969, 1971). One key finding of these new models is that the basic implication of Merton (1971) - that the presence of human capital creates a strong incentive to invest in risky securities when human capital is abundant, that is, early in the life-cycle, and to rebalance away from such securities as people get older and their human capital shrinks - carries over to more complex environments than the complete market setting studied by Merton (1971). This implication holds in models with labor income risk and incomplete markets as well as other realistic features such as liquidity constraints or more general preference representations. ${ }^{\text {[ }}$ All of these models consistently predict that individuals should rebalance toward a safer portfolio as they approach retirement, the driving force being the life-cycle pattern of human capital. ${ }^{\square}$ However, these features alone are not enough to induce investors to leave the stock market altogether: many of the new models continue to predict stock market participation at all ages, in line with the early models.

Microeconomic data on household portfolios, however, seem to depart from these predictions. First, not only is participation in the stock market limited at all ages, but it tends to follow a life-cycle pattern - in many instances a hump-shaped one (Guiso, Haliassos, and Jappelli (2002)). Second, the share of financial wealth invested in stocks (and mutual funds), the risky share, tends to vary little with age, although the specific empirical pattern is subject to controversy. Summarizing evidence from several countries, Guiso, Haliassos, and Jappelli (2002) argue that the age profile of the risky share is relatively flat, albeit in some instances "there does seem to be some moderate rebalancing of the portfolio away from risky securities" as people age. Thus, a reasonable characterization of the empirical findings is that participation in the stock market follows a hump-shaped profile, while the risky share varies little, if at all, with age. The empirical finding that people do not rebalance their risky share over the life-cycle is particularly puzzling because rebalancing is implied by an indisputable fact of life - the decrease in the stock of human capital as people age.

\footnotetext{
${ }^{1}$ This is shown by several computational models of life-cycle portfolio investments that amend the SamuelsonMerton model along one or more dimensions. See Benzoni, Collin-Dutresne, and Goldstein (2007), Campbell and Viceira (2001), Cocco, Gomes, and Maenhout (2005), Davis, Kubler, and Willen (2006), Gakidis (1998), Gomes and Michaelides (2003, 2005), Gomes, Kotlikott, and Viceira (2008), Haliassos and Michaelides (2002), Heaton and Lucas (1997), Polkovnichenko (2007), Storesletten, Telmer, and Yaron (2007), and Viceira (2007).

${ }^{2}$ A declining life-cycle portfolio profile may also be generated by features other than the life-cycle of human capital, for instance, by greater labor supply flexibility when young (Bodie, Merton, and Samuelson (1992)), by a departure from CRRA utility (Gollier and Zeckhamser (2002)), by life-cycle patterns of risk aversion and background risk, as well as by predictability of stock returns (Camphell and Viceira (1999, 2002), Kandel and Stambaugh (1199.5)). While these factors may contribute to a rebalancing motive over the life-cycle, the most agreed upon factor is the life-cycle of human capital.
} 
It also runs counter to recent evidence that human capital drives financial risk-taking positively (Calvet and Sodini (2014)).

While the lack of participation is a robust feature of the data, there are at least three reasons to doubt the empirical patterns as regards age in terms of both participation and the risky share. First, most of the available evidence comes from cross-sectional data. Inferences about the age pattern of the portfolio must therefore be drawn from comparisons of the portfolio holdings of individuals of different age, rather than of the same individual as his age varies. Panel data may help address this issue, although adding an extra source of variation to the data (time) also adds the need to model it. If reasonable restrictions on time effects can be imposed, the effect of age can then be distinguished from that of birth-year. Second, most studies ignore the fact that the risky share is only defined for stock market participants (or risky asset markets more broadly) and that participation in risky asset markets is an endogenous choice. Thus, uncontrolled selection, if correlated with age, may be responsible for the failure to find evidence of rebalancing of the risky share. Third, the evidence so far is based primarily on household surveys, which are notoriously prone to measurement problems. Most importantly, measurement and reporting errors are likely to be correlated with age, obscuring age patterns present in the true data. ${ }^{\text {? }}$

In this paper, we try to overcome these problems. To do so we assemble a new database that draws on administrative records from the Norwegian Tax Registry (NTR). Because Norwegian households are subject to a wealth tax, they have to report to the tax authority all their asset holdings, real and financial, at the level of the single instrument at the end of the year. We draw a random sample of $20 \%$ of the 1995 population of Norwegian households and then follow these households for 15 years until 2009. This data set reports the complete portfolio of Norwegian people and is similar in structure and content to the one used by Calvet, Campbell, and Sodini (2007), but it spans many more years - an essential feature when studying the life-cycle profile of portfolio allocation. Because the data set is sourced from the tax registry, measurement error is minimized. The main cause of nonreporting or underreporting should stem from incentives to evade the wealth tax, but, as we argue in Section $\mathbb{\mathbb { l }}$, the way the wealth tax is collected in Norway suggests that tax evasion is unlikely to be an issue. Finally, since the entire population of Norwegian taxpayers has to report to the NTR, there is little attrition in the panel apart from that due to death, migration to another country, or divorce.

After taking into account the endogeneity of the participation decision and modeling cohort effects, we find that both participation in the stock market and the risky share show important life-cycle patterns. As in other studies, we also find little asset decumulation after retirement and a hump-shaped life-cycle profile in participation, besides limited stock market participation at all

\footnotetext{
${ }^{3}$ Two exceptions are Ameriks and Keldes (2002), who use a panel of TIAA-CREF contributors, and Agnew, Balduzzi, and Sundén (2003), who use a four-year panel data set of people who hold 401k retirement accounts. In principle, they can distinguish between age, time, and cohort effects. Because they use administrative data, underreporting of assets is not a major issue. However, TIAA-CREF and the 401k retirement accounts only report assets contributed to the program, not the complete portfolios of these individuals, and there is no obvious reason why the portfolio allocation in pension savings should be the same as the allocation in other financial assets or follow the same age profile (indeed it does not; see Guiso and Sodini (2013)).
} 
ages. But we also find that the average risky share of those that participate varies significantly with investor age. Specifically, the risky share is high and fairly constant during young ages, at a level just below 50\%, while, investors reduce their risky share at a steady pace of somewhat less than one percentage point per year from about age 45 until they reach retirement. During retirement, investors who remain in the stock market keep their risky share fairly flat at around $30 \%$. In contrast, participation in the stock market increases rapidly with age when young, reaching a value of around $60 \%$ at age 45 , and stays roughly constant or increases slightly until retirement. As soon as investors leave the labor market and retire, they also start exiting the stock market.

Our data suggest a double adjustment as people age, with a very specific timing: households rebalance their portfolio away from stocks before they reach retirement and exit the stock market after retirement. Existing calibrated life-cycle models can account for the first behavior but not the second. We show that extending the model of Cocco, Gomes, and Maenhout (2005) to incorporate a (relatively large) per-period participation cost generates substantial, limited participation among the young but not enough exit after retirement. However, when we also add a small probability of a large loss when investing in stocks - a "disaster" event - close to the frequency of large collapses in the Norwegian stock market over the past century, the model predicts a joint pattern in the level of participation and the risky share over the life-cycle similar to that observed in the data, with early rebalancing of the risky share followed by a pronounced exit from risky asset markets after retirement.

Numerical simulations reveal that a combination of a small participation cost, a small probability of a large loss, and a relatively large risk aversion can well explain the shape and location of the lifecycle profile of the average household's stock market participation and risky share. Furthermore, when we estimate the parameters using an extended version of the model that also allows for a bequest motive to simultaneously target the age profiles of participation, the risky share, and the level of wealth, we match the three profiles reasonably well, although the model still generates more financial wealth decumulation during retirement than we observe in the data.

The rest of the paper is organized as follows. Section $\square$ discusses the Norwegian registry data and presents descriptive evidence on the portfolio life-cycle pattern. Section Wlays out our methodology for estimating the life-cycle portfolio profile and presents estimation results. Section $\mathbb{W}$ shows how an extended calibrated life-cycle model can account for the portfolio pattern observed in the data. Section $\mathbb{\nabla}$ presents properties of the model and the outcome of the model estimation. Section $\nabla$ summarizes our contribution and draws implications for future research.

\footnotetext{
${ }^{4}$ Some models address limited participation among the young by allowing for a once-and-for-all fixed cost of participation (Alan $(2006)$ ), for long-run co-integration between labor income and stock market returns (Benzoni, Collin-Dutresne, and (Goldstein (2007)), or for costly access to the loan market (Davis, Kubler, and Willen (2006)). None of these models, however, can deal with exit from the stock market as people retire and hence cannot explain the hump shape in participation over the life-cycle or the timing of rebalancing in the optimal risky share or in participation that we observe in the data. In addition, these models tend to predict too high a share in stocks among stockholders at some point over the life-cycle.
} 


\section{Data}

The empirical study of household portfolio allocations over the life-cycle entails formidable data requirements. Ideally, one would employ data on households' complete portfolio holdings that cover a long time span and are free from measurement and reporting errors. The NTR data that we use in our empirical analysis come very close to meeting these requirements. Because households in Norway are subject to a wealth tax, they are required to report their complete wealth holdings to the tax authority every year. We merge this information with administrative records of individual demographic characteristics and earnings to obtain a unique panel data set spanning the years 1995 to 2009.

\section{A. The Norwegian Administrative Data}

Each year, before tax returns are filed in April, employers, banks, brokers, insurance companies, and any other financial intermediaries send information both to the individual and to the tax authority on the value of the asset owned by the individual and administered by the employer or intermediary, as well as on the income earned on these assets. If an individual holds no stocks, the tax authority sends a pre-filled tax form to the individual for approval. If the individual does not respond, the tax authority considers the information in the prefilled form as approved. In 2009, as many as 2 million people in Norway (60\% of tax payers) belonged in this category. If the individual owns stocks, then he has to fill in the tax return, including calculations of capital gains/losses and deduction claims. The statement is sent back to the tax authority, which, as in the previous case, receives all the basic information from employers and intermediaries and thus

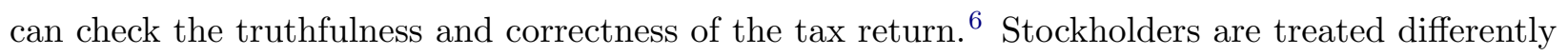
because the government wants to reduce both the time necessary to fill in more complex tax statements and the risk of litigation due to miscalculated deductions of capital losses and taxes on capital gains. This procedure, particularly the fact that financial institutions supply information about their customers' financial assets directly to the tax authority, makes tax evasion very difficult and thus nonreporting or underreporting of asset holdings likely to be negligible. ${ }^{\mathbb{1}}$

Tax statements on both labor income in the previous year and asset holdings as of December 31 of the previous year are filed separately by each taxpayer in the population, and also for married couples. Besides information on assets, the administrative data contain information on demographic characteristics of all individuals, as well as an identifier of the family they belong to. We can therefore aggregate assets at the household level. For our purposes, we define a household as a married couple (or a cohabiting couple, possibly with children) and identify its age (and other

\footnotetext{
${ }^{5}$ See Norwegian Tax Administration annual report: http://www. skatteetaten.no/Upload/annual-report-2009.pdf.

${ }^{6}$ Internet brokers offer their customers calculations of realized returns over the previous year for free.

${ }^{7}$ Since 2000, all of this has been done electronically; prior to 2000 tax reports were recorded on paper forms.

${ }^{8}$ The only exception is if households own and do not report foreign investments. Calvet, Campbell, and Sodinil (2007) discuss this issue for Sweden and conclude that unreported foreign investments represent a modest fraction of households' assets, except perhaps for the very wealthy.
} 
characteristics such as education) with that of the husband. The term "cohort" refers to the birth year of the husband. To extract a large but still computationally manageable sample, we first retain all households defined as above with both spouses alive as of 1995 and with at least NOK 3,000 in financial assets (USD 480 in 1995 prices). We then randomly sample $20 \%$ of them to obtain an initial reference sample of 164,015 households, which we follow over the subsequent 15 years until 2009. Households that exit the sample because individuals die, migrate, or divorce are not replaced. Overall, the sample contains 1,804,115 household-year observations. ${ }^{\text {[9 }}$

We focus on the financial portfolio and distinguish between bank deposits, treasuries and bonds, stocks (of listed and nonlisted companies), mutual funds, and money market funds. ${ }^{\text {⿴囗⿰丿㇄口 }}$ Following the literature, we consider a two-asset portfolio: we define risky assets as the sum of mutual funds with a stock component and directly held stocks, and risk-free assets as the sum of bank deposits, money market funds, and bonds. A household's financial assets are given by the sum of these two categories, which we also refer to as a household's financial wealth. $\square$

- Table [ here -

Table I provides summary statistics for the full household sample in 1995 . The average household's age is 51 years. The highest education level obtained is a high school diploma for $53 \%$ of the sample, and a college degree for $24 \%$ of the sample. The average Norwegian household holds around USD 38,000 (1995 prices) in financial assets. Net worth, the sum of financial assets and real estate net of debt, amounts to USD 120,000, of which about two-thirds is real estate. ${ }^{\square}$ The financial portfolio of the average household comprises mostly safe assets, which account for $63 \%$ of average financial assets. We define a participant in risky asset markets to be a household with at least USD 160 (1995 prices) in risky assets. The rate of participation in risky asset markets is $33 \%$ (37\% if we include all those with positive risky assets), which reflects the fact that $23 \%$ of the population holds stocks directly and $22 \%$ participates via mutual funds (in 1995, mutual funds were not as widespread as direct stock-holding among Norwegian households). Among participants, the average share invested in risky assets is $32 \%$, while mutual funds account for $9 \%$; similar figures prevail in other European countries, as documented in Guiso, Haliassos, and .Jappelli (2002).

\footnotetext{
${ }^{9}$ The quality of the data is similar to that of the Swedish data studied by Calvet, Campbell, and Sodinil (2007). Until 2007, Sweden like Norway collected taxes on both individual income and wealth. In 2007, however, Sweden abandoned the wealth tax, leaving Norway as the only Scandinavian country with this arrangement.

${ }^{10}$ Very few households (67 observations in the full sample) hold more sophisticated instruments such as futures and options. We exclude them from the sample.

${ }^{11}$ Private old age pensions were not widespread in Norway during our observation window. All Norwegian citizens are entitled to a state pension from the age of 67 in accordance with the National Insurance Act. The financing of this system is through a pay-as-you-go system, but it is currently undergoing reforms and evolving toward a defined contribution system to be fully implemented by 2025. Furthermore, early retirement schemes are widespread in Norway and workers may be eligible for these from the age of 62 ; see, for example, Vestad (2013). Pension benefits are indexed to the average wage growth of the economy.

${ }^{12}$ The value of real estate is a proxy based on the reported tax values of Norwegian households and is not updated every year. To obtain our estimate, we divide the reported tax value of real estate by 0.25 . This follows the guidelines of the Norwegian Tax Administration, which state that the tax value of real estate shall not exceed $30 \%$ of its market value.
} 
Although there is sample attrition at an average annual rate of $3 \%$, we can track two-thirds of the households sampled in 1995 all the way to 2009. The main reason for exiting the sample is the death of one spouse $(62 \%)$, which is consistent with the high average age at exit (63 years, see

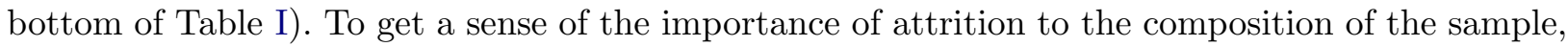

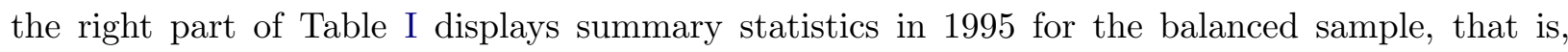
households that are present continuously over the 1995 to 2009 period. Not surprisingly, balanced panel households are younger in 1995 and slightly better educated. However, the value of asset holdings, portfolio allocation, and risky asset market participation is similar across the two groups, suggesting that attrition is fairly random.

\section{B. Portfolio Life-Cycle Patterns by Cohort: Descriptive Evidence}

Figure 1 plots the age profile of participation in risky asset markets for selected cohorts at fiveyear intervals, beginning with the cohort born in 1970 and 25 years old in 1995, the first sample year. Since we are able to follow each cohort for 15 years, plotting the raw data provides a good picture of the life-cycle portfolio pattern.

Consider the first cohort born in 1970, whose members were 25 years old in 1995 . Only slightly more than $10 \%$ of these households were participating in risky asset markets in 1995. However, the share of participants in this cohort increases substantially over the next five years, such that when this cohort was aged 30, almost $50 \%$ of households own risky assets. Clearly, this pattern is consistent with a marked age effect (an increase in participation with age), with strong time effects (an increase in participation with improvements in market conditions, for example, the boom in the mutual fund industry), as well as with a cohort-specific pattern. If this were the only cohort observed, these effects would be hard to disentangle as time and age evolve in parallel and thus we could not make any claim regarding whether the increase in participation rate is cohort-specific, reflects a pure age effect, or is due to a common time trend that affects all cohorts in the years 1995 to 2009.

- Figure [1 here -

The next plotted cohort, households born in 1965, also reveals a steep increase in average participation during the first years of our sample for these households. This suggests that the increase in participation over age/time is unlikely to be cohort-specific. However, it is still unclear whether this increase in participation is due to an age effect or to a common time trend. Comparing the evolution of participation across cohorts suggests that time effects are likely to be important. For instance, all cohorts experience a marked increase in participation during the first years of our sample, even those born in 1920 that are typically in the process of exiting the risky asset market at the time we observe them. And there is a drop during the 2001 recession even among those born in the 1960s and 1970s, who would typically be entering the stock market. The graphical evidence also suggests that cohort effects are likely to play an important role. In fact, compared to younger 
cohorts, older cohorts at the same age have lower participation rates. In Section $\mathbb{W}$, we describe our empirical strategy to separate age, time, and cohort effects.

As a next step in the descriptive analysis of the life-cycle patterns of participation, we consider two sets of measures of entry into and exit from the stock market, as defined in Table W. These two sets of measures are plotted in Figure 2. The first set of measures capture entry (exit) in a given year regardless of households' past (future) participation pattern. The second set of measures capture entry (exit) that was not preceded (followed) by a previous entry (subsequent exit), that is, first-time entry and permanent exit.

- Table Wl here -

- Figure 2 here -

First-time entry is very high at the beginning of the life-cycle, with a peak at 13\%, after which it drops steadily. It is lower than total entry, particularly for middle-aged households. In contrast, permanent exit is low at the beginning of the life-cycle and increases sharply after retirement. ${ }^{\text {[1 }}$ By comparing the two measures, Figure $\square$ shows that, early in life, temporary entry and exit are common phenomena. Among households in their early 30s, $13 \%$ enter the stock market and most of them enter for the first time, and the fraction of young households that sell all risky assets to return to the stock market later in life is almost five times the fraction of households that exit permanently. The existence of intermittent participation suggests a role for per-period participation costs. 14

- Figure 3 here -

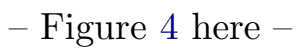

Figure 3 plots (for the same cohorts as in Figure 1) the risky share among households that participate in the stock market, that is, the conditional risky share. Looking at the overall age pattern, the figure suggests that once people enter risky asset markets, they invest a relatively large share in risky assets, hold this share fairly constant over the early part of the life-cycle, and then reduce this share as they age. Comparing across cohorts over time suggests that cohort effects for the conditional risky share are less pronounced than those that characterize the participation profile (Figure $\mathbb{1}$ ), while time effects are strong, reflecting movements in stock prices that are only partially undone by active rebalancing (Calvet, Campbell, and Sodinil (200.9)). In contrast, the raw data for the risky share suggest that there is substantial rebalancing over the life-cycle, particularly as households approach retirement.

\footnotetext{
${ }^{13}$ Because of the limited time span of our data, the second set of entry and exit measures may be affected by censoring. Censoring would bias upward both the first-time entry rate at young age and the permanent exit rate at old age.

${ }^{14}$ The higher variability at the two ends of the age range both in Figures $\square$ and 3 reflects the fact that at the two ends of the age distribution there is a limited number of observations.
} 
We complete our descriptive analysis by plotting in Figure 4 households' financial wealth for the same cohorts. To account for the bias induced by the well-known correlation between wealth and mortality, we adjust the value of households' assets using the methodology outlined in Attanasio and Hoynes (2000) (see Appendix $\mathbb{B}$ ). This adjustment is also necessary to facilitate comparison of the life-cycle wealth profile in the data to that generated by the model that we propose in Section III, since no relationship between mortality and wealth exists in the model. The plotted profiles suggest that, for young cohorts, financial wealth increases sharply with age and time, and that younger cohorts tend to be wealthier than older ones. Figure $\mathbb{\text { ⿴l }}$ further suggests only a mild (if any) decumulation of financial wealth in old age. In Section $\mathbb{W}$ we estimate the age-wealth profile, taking cohort and time effects into account.

\section{Estimation}

The descriptive evidence suggests the existence of marked life-cycle patterns for both the participation decision and the conditional risky share of households' portfolios, as well as for financial wealth itself. However, it does not address two key issues: the endogeneity of participation in risky asset markets and the separation of time, age, and cohort effects. In this section we discuss how we address these issues in order to pin down the age profile of participation in risky asset markets, the age profile of the conditional risky share, and the age profile of financial wealth.

\section{A. Methodology: Limited Asset Market Participation}

It is well established that not all households participate in risky asset markets. So far, empirical studies of the life-cycle profile of household portfolios have neglected the endogeneity of participation when estimating the life-cycle profile of the risky share (Ameriks and Zeldes (2002)). This is unfortunate because unaccounted selection can bias the relationship between the risky share and age, for instance, by hiding it. Until recently, calibrated life-cycle models have also ignored limited participation in risky asset markets by abstracting from participation costs. Below, we remedy this deficiency by introducing a per-period participation cost in a standard life-cycle portfolio model.

We address the joint decision of whether to participate and how much financial wealth to allocate to risky assets using a Heckman selection model. To do so, we estimate a probit model for household participation in risky asset markets and a share equation for the participants, taking selection into account. To achieve identification, we let the participation decision be affected by (the lagged value of) the overall lifetime wealth of the individual, which is obtained by summing accumulated assets and an estimate of the individual stock of human wealth (see Appendix $\mathbb{A}$ for details about the estimation of human wealth), and we impose the restriction that lifetime wealth does not affect the risky share (of financial wealth) conditional on participation. This exclusion restriction is inspired by Merton (1.971), whose model implies that, in the presence of labor income, risky assets as a share of total lifetime wealth are constant over the life-cycle and thus independent of lifetime wealth. The risky share of financial wealth depends on the ratio of human to financial 
wealth, which evolves over the life-cycle, but not on the level of lifetime wealth. Hence, controlling for age to account for the life-cycle of the human to financial wealth ratio, the risky share should be unaffected by total lifetime resources (see Appendix B]). We impose this restriction. Of course, with a fixed participation cost, the decision to participate depends on individual wealth (Vissingगørgensen (2002)).

\section{B. Methodology: Treatment of Cohort Effects}

Even though we observe households' investments and wealth over a substantial portion of their life span, it is well known that it is not possible, without additional restrictions, to identify cohort, time, and age effects. This issue is extensively discussed in Ameriks and Zeldes (2002) in the context of estimates of the life-cycle profile of portfolio choice. In fact, calendar year, age, and birth year are linearly related. Since the linear relationship "calendar year"="age" + "birth year" is at the heart of the identification problem, most solutions have proceeded by making assumptions or using prior information to break this multicollinearity, allowing the use of standard regression techniques. One strategy is to respecify the model to make it nonlinear or to estimate it in first differences, another is to impose parametric restrictions, and a third is to replace the dummies that capture one of the effects with variables meant to capture a causal mechanism for that effect. ${ }^{\mathbb{5}}$ Here, we rely on both the second (impose parametric restrictions) and the third (explicitly model cohort effects) strategies to identify the age profiles of the portfolio, and we rely on the third strategy to identify the age profile of wealth.

With respect to the parametric restrictions, we follow Deaton and Paxson (1994) and impose the restriction that time effects sum to zero once the variables have been de-trended. Since our data cover several years, we should be able to separate trend and cycle, and thus be reasonably confident about the decomposition of age, time, and cohort effects based on this restriction (Deaton (19.97)).

To implement the other strategy to identify the age profile of participation and the risky share, we build on recent research by Giuliano and Spilimbergo (2014), who find that generations that grow up in recessions have systematically different socioeconomic beliefs than generations who grow up in booms, suggesting important birth-year effects on beliefs and preferences. Even closer to the spirit of our approach is the study by Malmendier and Nagel (2011). They show that households that experience higher stock market returns early in life are more likely to participate in the stock market and, conditional on participation, invest a higher fraction of their wealth in risky assets. Furthermore, when asked, they report a higher willingness to bear risk, possibly because early experiences have enduring effects on risk preferences. This evidence suggests that one can rely

\footnotetext{
${ }^{15}$ The use of one or another strategy is context specific, with the choice depending on what assumption appears reasonable in the given context. Some recent papers propose generic, contest-independent solutions. For example, Yang, Fu, and Land (2004) and Yang et al. (2008) propose what they call the intrinsic estimator. Browning, Crawtord, and Knoet (2012) show that when the range of the variable(s) of interest is bounded, the time, age, and cohort effects are partially identified in the sense that they are confined to a closed convex set. They then propose using a maximum entropy estimator to achieve point identification within that set.
} 
on variation in experienced stock market returns among members of our sample to model cohort effects. Accordingly, we use stock market returns (a weighted average of the Oslo Stock Exchange, $80 \%$, and the MSCI World Index, 20\%) experienced during the household heads' formative years (between ages 18 and 25, as in Giuliano and Spilimbergo (2014)) as our proxy for cohort effects. [1] As we will show below, these returns significantly affect the decision of whether to enter risky asset markets and to a lesser extent the conditional risky share. We can thereby identify unrestricted time and age effects.

To pin down the age profile of wealth, we follow Kapteyn, Alessie, and Lusardi (2005) and Jappelli (1999) and use a measure of the general macroeconomic conditions at the time an individual entered the labor market as a proxy for cohort effects, and we allow for unrestricted time effects. The long-term effects of macroeconomic conditions at the time of entry to the labor market on individuals' careers are documented for both the U.S. (Oreopoulos, von Wachter, and Heisz (2012)) and Norway (Liu, Salvanes, and Sorensen (2016)).

\section{Empirical Model Specification}

We specify the following two-equation model for the risky share of financial wealth conditional on participation, $s_{\text {iact }}$, and for the decision to participate, $P_{\text {iact }}$, by household $i$ aged $a$ belonging to cohort $c$ in year $t$ :

$$
\begin{aligned}
s_{\text {iact }}= & \beta_{a} A_{a}+\beta_{c} C_{c}+\beta_{t} D_{t}+\beta_{0} \text { Trend }+\theta Z_{\text {iact }}+\theta_{2} \lambda_{\text {iact }}+\varepsilon_{\text {iact }} \\
\operatorname{prob}\left(P_{\text {iact }}=1 \mid x\right) & =\operatorname{prob}\left(P_{\text {iact }}^{\star}>0 \mid x\right) \\
& =\operatorname{prob}\left(\delta_{a} A_{a}+\delta_{c} C_{c}+\delta_{t} D_{t}+\delta_{0} \text { Trend }+\vartheta Z_{\text {iact }}+\vartheta_{2} L_{\text {iact }}+\eta_{\text {iact }}>0\right),
\end{aligned}
$$

where $P_{\text {iact }}$ is a dummy variable that takes the value of one for households with positive risky assets and zero otherwise, $P_{\text {iact }}^{*}$ is the unobserved latent variable triggering participation when positive, $A_{a}, C_{c}$, and $D_{t}$ are dummies for age, cohort, and time, Trend is a time trend, $Z_{\text {iact }}$ is a vector of individual controls (family demographics and a homeownership dummy to account for interactions between portfolio composition and housing as in Cocco (2005)), $\lambda_{\text {iact }}$ is the inverse Mills ratio computed from the participation equation, $L_{i a c t}$ is an estimate of lifetime wealth, and $\varepsilon_{i a c t}$ and $\eta_{\text {iact }}$ are error terms.

When we use the Deaton and Paxson (1994) method to separate age, time, and cohort effects, we also impose the restriction $\sum \beta_{t}=\sum \delta_{t}=0$; when we model cohort effects as a function of experienced stock market returns $\left(R_{c}\right)$, we replace $C_{c}$ with $R_{c}$ and set $\beta_{0}=\delta_{0}=0$. Assuming $\eta_{\text {iact }}$ is normally distributed, we estimate the above model using a two-stage Heckman estimator.

Turning to the financial wealth profile, we estimate

\footnotetext{
${ }^{16}$ See Internet Appendix Section I for more details on how we compute these weights. The Internet Appendix is available in the online version of the article on the Journal of Finance website.
} 


$$
z_{i a c t}=\gamma_{a} A_{a}+\gamma G_{c}+\gamma_{t} D_{t}+\psi Z_{i a c t}+\nu_{i a c t}
$$

where $z_{\text {iact }}$ is the value of the financial wealth held by household $i$ aged $a$ belonging to cohort $c$ in year $t, G_{c}$ is a measure of the macroeconomic conditions cohort $c$ faced when entering the labor market, and the other variables are as defined above.

\section{Results from Estimating Life-Cycle Patterns}

\section{D.1. Risky Asset Market Participation and Conditional Risky Share}

Table $\mathbb{W}$ reports the estimates of the Heckman selection model. Age and time effects and the coefficients on the other controls are reported in the Internet Appendix for the sake of brevity. The first two columns show the estimates using the Deaton and Paxson (1994) restriction. In the participation equation (column (1)), the time trend is positive, significant, and economically important. In particular, it implies that in the final year of the sample, the average participation rate is 18 percentage points higher than at the beginning of the sample. The trend is negative and statistically significant, but economically small in the conditional share estimate. Unrestricted cohort effects are significant both for the participation decision and for the risky asset share, but particularly for the former (see the $\chi^{2}$ test at the bottom of the table). Interestingly, the probability that the household participates in the risky asset markets is strongly affected by the level of lifetime wealth, which suggests that, as expected, the identifying strategy is both consistent with the presence of fixed participation costs and powerful. In addition, the significance of the inverse Mills ratio highlights the importance of adjusting for selection to obtain consistent estimates of the age profile of the conditional risky share.

- Table WU here -

Columns (3) and (4) show the estimates obtained by modeling cohort effects explicitly. Cohort effects captured by stock market returns experienced in youth have a positive and significant effect on the participation decision but not on the share of financial wealth invested in risky assets by the participants. Economically, investors who grow up in years of low stock market returns (5th percentile of the historical return distribution) are 6.12 percentage points less likely to own risky assets compared to investors exposed in youth to high stock market returns (95th percentile of the historical return distribution). The effects of lifetime wealth on participation and of the inverse Mills ratio on the conditional share are essentially the same as when imposing the Deaton and Paxson (1994) restriction.

The age profiles for participation and the portfolio share obtained from the estimated Heckman model using these two strategies are plotted in Figure $5 .{ }^{[17}$ Independently of the method used to separate age from time and cohort effects, the figures document a distinct hump-shaped age pattern

\footnotetext{
${ }^{17}$ Obviously, since the value of lifetime wealth depends on age, it contributes to confer a lifetime profile to the participation rate, in addition to the effect that the age dummies have on it. Figure 5 reflects this.
} 
of asset market participation over the life-cycle. Among younger households, the participation rate (right scale) increases steadily until the age of approximately 40 and then much more gradually, peaking when households are in their $60 \mathrm{~s}$, just prior to retirement. At its peak, the participation rate is around 60\%, after which the participation in risky asset markets drops almost linearly until the age of 80 . The age pattern of the conditional risky share is remarkably different. The share starts high at a very young age and remains relatively constant for about a decade, after which individuals rebalance the share in risky assets, first gradually and then somewhat faster until retirement (around age 65), when the risky share stabilizes. During the transition, the share is reduced at a speed of around half a percentage point a year (if the cohort proxy is used, or twothirds of a percentage point using the Deaton and Paxson (19.94) restriction), half the adjustment speed that is typically recommended by practitioners.

The most interesting feature of the two profiles is the timing of the portfolio adjustment along the two margins, the intensive margin of the share invested in risky assets and the extensive margin of participation in risky asset markets. Our estimates show that, consistent with life-cycle portfolio models with labor income, households do limit exposure to the stock market by rebalancing their financial portfolio as they approach retirement and their stock of human capital falls. But they also adjust along the other margin, by leaving the stock market altogether as they age. However, this adjustment only starts after the household retires, precisely when the adjustment along the intensive margin stops. The pattern and timing of this double adjustment that we document is the focus of the life-cycle portfolio model that we develop in Section $\mathbb{W}$.

When we contrast the life-cycle profiles of the risky share and participation estimated applying the two methods, we see that they deliver very similar participation profiles. However, the Deaton and Paxson (1994) method predicts a significantly higher risky share, particularly among the young.

Since the age profiles of human capital differ in level and shape according to education (see Appendix (A), this may result in different risky share and participation profiles, although their main qualitative features should be preserved since human wealth declines with age independently of education. As a robustness check, we estimate the model presented in Section ‥ d separately for three education groups imposing the Deaton and Paxson (1994) restriction (the results are similar using the other method). More educated households tend to participate more and invest larger shares in risky assets conditional on participation. However, the age profiles of the risky share and participation preserve the dual adjustment pattern that we document for the full sample, with the conditional risky share being relatively flat during mid life and then declining until retirement, and the participation profile being hump-shaped with exit from the stock market beginning only after households have already adjusted the risky share and are close to retirement or have just retired.

Finally, we apply the same methodology to separate age from time and cohort effects in the entry and exit patterns shown in Figure 2. We regress the two sets of measures of entry to and exit from risky asset markets on age dummies, cohort dummies, and calendar year fixed effects, imposing the Deaton-Paxson restriction discussed in Section $\mathbb{L}$.B. The estimated profiles are reported in Figure 6. Interestingly, once we account for cohort and time effects, the entry age profiles are hump-shaped 
with a peak around age 40, while the exit age profiles are somewhat U-shaped.

- Figure 5 here -

- Figure [6 here -

\section{D.2. Financial Wealth Profile}

Obtaining a complete picture of the life-cycle portfolio choice of households also involves estimating the life-cycle profile of households' financial wealth. We estimate it controlling for real estate wealth. Our left-hand side is the level of financial wealth, which is multiplied by the inverse of the estimated survival probabilities to correct for the bias induced by the well-known correlation between wealth and mortality (Shorrocks (1975)). We proxy for cohort effects using the macroeconomic conditions the cohort faced when entering the labor market, measured by the deviation from trend GDP per capita at ages 15 to 30 for each cohort. Similar to Kapteyn, Alessie, and Lusardil (2005) and Jappelli (1999), we find that these cohort effects are significant and economically important for the wealth levels of the household later in life. The estimated life-cycle profile of financial wealth is shown in Figure 7. It is steeply increasing earlier in life and, as is typical in this literature (e.g., Kaptevn, Alessie, and Lusardil (2005), Jappelli (1999)), it shows only mild asset decumulation after retirement, a well-documented empirical fact (e.g., Bernheim (1987)). In the model below, we try to capture this feature by allowing for survival risk as well as for a bequest motive.

- Figure 7 here -

\section{Model}

The previous sections establish novel stylized facts about the life-cycle profile of Norwegian households' asset market participation and portfolio composition. Existing calibrated life-cycle models can account for the rebalancing of the risky share away from stocks over the life-cycle, but not for the joint patterns of adjustment of the risky share and of participation in risky asset markets. In this section, we present a life-cycle model that can account for the broad features of the life-cycle profile of portfolio allocations along both margins and, in one version, also for the age profile of financial wealth.

To facilitate comparison with the literature, we use the workhorse portfolio choice model of Cocco, Gomes, and Maenhout (2005), but add two features. First, we allow for a fixed per-period stock market participation cost. This provides a motive for exiting the stock market as people 
age in addition to inducing limited participation in the stock market at young ages. ${ }^{18}$ Second, we allow for a probability of a negative tail (i.e., disaster) event when investing in stocks. ${ }^{\mathbb{4}}$ One interpretation, pursued by Barro (2006) and Rietz (1988), argues that households anticipate rare but big losses due to stock market crashes, that is, they attach a small positive probability to disasters that entail large stock market losses. We find support for this interpretation by showing that, based on past stock market history, Norwegian households have good reasons to attach a small probability to large stock market losses. As we will see, the tail event is key if the model is to generate enough exit from the stock market after retirement, as well as to help address the "too" high conditional risky share at young and middle ages that a workhorse portfolio choice model typically generates. ${ }^{20}$

\section{A. Households}

In the model economy, households work from age $T^{b}$ until age $T^{r}$, after which they retire. Households face uncertainty with respect to the number of years they live. We model this component as in Hubbard, Skinner, and Zeldes (19.95) and denote by $p_{a}$ the probability that the household is still alive at age $a+1$, conditional on being alive at age $a$. Households' objective function is the sum of discounted life-time utility:

$$
E \sum_{a=T^{b}}^{T} \underbrace{\delta^{a}\left(\prod_{j=0}^{a-1} p_{j}\right)}_{\beta_{a}} U\left(c_{i, a}\right),
$$

\footnotetext{
${ }^{18}$ Haliassos and Michaelides (2003) and Gomes and Michaelides (2005) allow for a one-time fixed cost of participation over the consumer horizon but not for per-period costs. Some exit from the stock market after retirement may occur even without a per-period participation cost if households liquidate stocks in bulk to finance durable consumption purchases or to face unusual lumpy expenses, for example, health care (Alan (2006)). In general, however, absent participation costs, one should see a decumulation of both stocks and bonds and very little exit.

${ }^{19}$ Alan (2012) also studies life-cycle portfolio allocation allowing for participation costs and a disaster probability and estimates it structurally on U.S. data, using pseudo panel data constructed from various cross sections of the U.S. Survey of Consumer Finances. She finds that the model fits the data poorly. As she notices when comparing the simulated profile to that in the data, "What is particularly disturbing in this figure is that the model persistently generates a hump shape for shares and participation that does not exist in the data." However, it may be the case that the model does not need to be amended but that the data are unable to reveal the true life-cycle portfolio pattern due to the shortcomings of survey data discussed in the introduction.

${ }^{20}$ In principle, two alternative sources of tail risk matter for life-cycle savings and portfolio decisions: first, large, infrequent drops in labor income such as those resulting from unemployment spells, and second, large shocks to health expenditure. The first source can help explain low shares invested in stock at a young age (Cocco, Gomes, and Maenhout (2005)) but does not generate exit at old age. Furthermore, Norway provides substantial unemployment insurance, which reduces the relevance of this source of tail risk at least in our case. In fact, Fagereng, Guiso, and Pistaferri (2016) find very small effects on stock investments of employment risk originating from firm bankruptcies in Norway.

Concerning large health shocks, they matter more at old age and could in principle help explain stock market exit and portfolio composition after retirement (Yogo (2009)). But while this type of risk is likely to be important in several countries, it is unlikely to be so in Norway because the Norwegian health system is quite generous and offers substantial insurance. It grants universal coverage and has the highest health expenditure per capita (USD 5,400 in 2010) in Europe. About $85 \%$ of health expenditures are covered by public insurance, with out-of-pocket expenses limited to $15 \%$ of the total. The latter reflects some gaps in the range of benefits (e.g., routine dental care services for adults are excluded), but older and disabled people are covered (see Ringard et al. (2013) for details).
} 
where $c_{i, a}$ is the consumption of household $i$ at age $a, \delta$ is the discount factor, and $\beta_{a}$ is the agedependent effective discount factor that takes into account the probability of death. We assume that the utility function is of the CRRA type; the degree of risk aversion is denoted by $\gamma$.

\section{B. Market Structure}

Financial markets are incomplete - households smooth consumption over the life-cycle by holding a risk-free asset and possibly a risky asset. The risk-free asset can be thought of as a real bond and has a time-invariant return $r_{f}$. We denote by $b_{i, a}$ the amount of bonds household $i$ holds at age $a$. Whereas the risk-free asset can be purchased and sold at no cost, we impose a fixed per-period participation cost $q$ to holding risky assets. The amount of risky assets held by household $i$ at age $a$ is denoted by $s_{i, a}$. The risky asset has a real return $r_{t}$ and a constant risk premium $r_{p} .{ }^{\text {.1] }}$ More specifically,

$$
r_{t}=r_{f}+r_{p}+\nu_{t}, \quad \nu \sim \mathcal{N}\left(0, \sigma_{r}^{2}\right)
$$

where $\nu_{t}$ is the period $t$ innovation to stock market returns drawn from a normal distribution. To account for the possibility of stock market crashes, we alter the stock return structure to allow for such events. With probability $\left(1-p_{\text {tail }}\right)$, the return on the risky asset will be drawn from the above stock return process $(\mathbb{G})$; with probability $p_{\text {tail }}$, a return $r_{\text {tail }}<0$ materializes. The stock return in the case of disaster is calibrated based on evidence that combines data on the frequency of stock market crashes in Norway and on the mean loss on stock investments suffered by Norwegian stockholders during the 2008 stock market crash, as described in Section W.E and Appendix $\mathbf{C}$.

Finally, we assume that households cannot borrow against future labor income and that the quantities of the two assets held are nonnegative:

$$
s_{i, a} \geq 0, \quad b_{i, a} \geq 0 .
$$

These constraints ensure that the share $\alpha_{i, a}$ of financial wealth invested in risky assets at age $a$ is positive and $\alpha_{i, a} \in[0,1]$.

\section{Household Problem}

\section{C.1. Household Budget Constraints}

Households start a period with a certain amount of labor income $\left(w_{i, a}\right)$ and financial wealth $\left(x_{i, a}\right)$. They decide how much to consume $\left(c_{i, a}\right)$ and to save in bonds $\left(b_{i, a+1}\right)$ if they do not participate in the stock market, and how much to consume and to save in bonds and equity $\left(s_{i, a+1}\right)$ if they participate in the stock market. Finally, they compare the indirect utility from participation and nonparticipation and decide whether to enter (stay) or exit the stock market.

\footnotetext{
${ }^{21}$ We calibrate the risk-free return and the equity premium using data from Norwegian bond and stock markets, as well as data from global stock markets (the MSCI World Index). See Section एW. $\mathbb{E}$ and Internet Appendix Section II for details.
} 
The budget constraint of a working age household is given by

$$
c_{i, a}+\mathbf{1}_{i, a+1}\left(s_{i, a+1}+q\right)+b_{i, a+1}=w_{i, a}+\left(1+r_{a}\right) \mathbf{1}_{i, a} s_{i, a}+\left(1+r_{f}\right) b_{i, a}, \quad a=T^{b}, \ldots, T^{r},
$$

where $\mathbf{1}_{i, a+1}$ is an indicator variable that takes the value of one if household $i$ participates in the stock market at age $a+1$ and zero if not, and $w_{i, a}$ stands for age-dependent labor income.

The budget constraint of a retired household is given by

$$
c_{i, a}+\mathbf{1}_{i, a+1}\left(s_{i, a+1}+q\right)+b_{i, a+1}=\phi_{r e t} w_{i, T^{r}}+\left(1+r_{a}\right) \mathbf{1}_{i, a} s_{i, a}+\left(1+r_{f}\right) b_{i, a}, \quad a=T^{r}+1, \ldots, T .
$$

Equation ([) is isomorphic with respect to (6) with the key difference being that labor income is now time-invariant: retirement income is a fixed share $\phi_{r e t}$ of the last working-age labor income of the household.

Finally, households maximize their objective function (3) subject to the constraints ([6) and ([7).

\section{C.2. The Labor Income Process}

During working age, households face uncertainty with regard to their labor income. The labor income process consists of two components, namely, a deterministic component and an idiosyncratic stochastic component:

$$
\log \left(w_{i, a}\right)=f(a)+v_{i, a}+\epsilon_{i, a}, \quad a=T^{b}, \ldots, T^{r}
$$

The deterministic component $f(a)$ is a function of age. The stochastic component is the sum of an idiosyncratic temporary shock $\epsilon_{i, a} \sim \mathcal{N}\left(0, \sigma_{\epsilon}^{2}\right)$ and a persistent shock $v_{i, a}$ that follows a random walk:

$$
v_{i, a}=v_{i, a-1}+u_{i, a}
$$

where $u_{i, a}$ is distributed as $\mathcal{N}\left(0, \sigma_{u}^{2}\right)$.

In contrast, during retirement, household labor income is assumed to be deterministic. Households' retirement income is a constant fraction $\phi_{\text {ret }}$ of the labor income in the last year of a households' working life:

$$
\log \left(w_{i, a}\right)=\log \left(\phi_{r e t}\right)+f\left(a=T^{r}\right)+v_{i, T^{r}}, \quad a=T^{r}+1, \ldots, T .
$$

The labor income process is estimated from our data set. Details of the estimation of the agedependent component of labor income and the variances of the transitory and permanent shocks to labor income are provided in Appendix $\mathbf{A}$. 


\section{C.3. Recursive Formulation}

The household problem presented above has a set of control variables $\left\{c_{i, a}, s_{i, a+1}, b_{i, a+1}, \mathbf{1}_{i, a+1}\right\}_{a=T^{b}}^{T}$ and a set of state variables $\left\{x_{i, a}, z_{i, a}\right\}_{a=T^{b}}^{T}$. We denote by $V_{a}^{i n}(x, v)$ the indirect utility of an $a$-year-old household that participates in the stock market, has a persistent labor income realization $v$ and financial wealth $x,{ }^{22}$ and is the solution to the following maximization problem:

$$
V_{a}^{i n}(x, v)=\max _{c, s^{\prime}, b^{\prime}} U(c)+\beta_{a+1} E_{v^{\prime}, x^{\prime}} V_{a+1}\left(x^{\prime}, v^{\prime}\right)
$$

where

$$
x^{\prime}=\left\{\begin{array}{l}
\left(1+r_{f}\right) b^{\prime}+(1+r) s^{\prime} \text { with probability }\left(1-p_{\text {tail }}\right) \\
\left(1+r_{f}\right) b^{\prime}+\left(1+r_{\text {tail }}\right) s^{\prime} \text { otherwise. }
\end{array}\right.
$$

The Bellman equation $V_{a}^{\text {out }}(x, v)$ is the indirect utility of an $a$-year-old household that does not invest in risky assets and has persistent labor income realization $v$ and financial wealth $x$. It is computed by solving the maximization problem

$$
V_{a}^{\text {out }}(x, v)=\max _{c, b^{\prime}} U(c)+\beta_{a+1} E_{v^{\prime}} V_{a+1}\left(x^{\prime}, v^{\prime}\right),
$$

where

$$
x^{\prime}=\left(1+r_{f}\right) b^{\prime} .
$$

The budget constraint of the household is given by

$$
c+\mathbf{1}^{\prime}\left(s^{\prime}+q\right)+b^{\prime}=w+x .
$$

The Bellman equation $V_{a}(x, v)$ for the household problem pins down the participation decision of the household:

$$
V_{a}(x, v)=\max _{\mathbf{1}^{\prime}=\{1,0\}}\left[V_{a}^{\text {in }}(x, v) ; V_{a}^{\text {out }}(x, v)\right] .
$$

The optimal policy correspondence $\mathbf{1}^{\prime}(x, v)$ for the participation decision is obtained as follows:

$$
\mathbf{1}^{\prime}(x, v)=\left\{\begin{array}{ll}
1 & \text { if } \bar{x} \in X_{p}(v) \\
0 & \text { otherwise. }
\end{array} \quad \text { where } X_{p}(v) \equiv\left\{\bar{x}(v): V_{a}^{\text {in }}(x, v)>V_{a}^{\text {out }}(x, v)\right\}\right.
$$

The maximization problem of retired households is analogous to the above formulation, with the only difference being that the uncertainty with regard to the realization of the income shocks is shut down and retirement income is a constant fraction $\phi_{\text {ret }}$ of the permanent component of labor income in the last working age year.

\footnotetext{
${ }^{22}$ We drop the indices $i$ and $a$ to lighten the notation, and index one-period-ahead variables using $x^{\prime}$ instead of $x_{a+1}$.
} 


\section{Bequest Motive}

In one version of the model, we allow households to derive utility from bequests according to a standard warm-glow bequest motive. This brings to the fore a third motive for intertemporal adjustment besides life-cycle consumption smoothing and the precautionary motive. The bequest motive gives our model more flexibility when we try to match the participation, asset allocation, and financial wealth life-cycle profiles that we estimate in Section ㄸ.D. In particular, the bequest motive helps match wealth dynamics during retirement. With the bequest motive, the household value function becomes

$$
V_{a}(x, v)=\frac{c^{1-\gamma}}{1-\gamma}+\delta E_{v^{\prime}, x^{\prime}}\left[p_{a+1} V_{a+1}\left(x^{\prime}, v^{\prime}\right)+\left(1-p_{a+1}\right) \frac{b}{1-\gamma}\left(\frac{x^{\prime}}{b}\right)^{1-\gamma}\right],
$$

where $b$ is the strength of the bequest motive and $p_{a+1}$ is the conditional survival probability.

\section{E. Parameterization}

Table $\mathbb{Z V}$ reports the parameters that we either fix or estimate outside our model. In accordance with Norwegian law, we set the retirement age $\left(T^{r}\right)$ at 67 for all households. The risk-free rate $\left(r_{f}\right)$ is set at $1.43 \%$, as documented by Klovland (2004) for Norway for the period 1900 to 2005. Dimson, Marsh, and Staunton (2008) provide real equity returns and standard deviations for the same period, but we also take into account Norwegians' exposure to foreign stocks. As we discuss in the Internet Appendix, Norwegian households are mostly exposed to the domestic stock market (about $80 \%$ ), but also have a significant fraction of their risky assets invested abroad (about 20\%). Taking this into account, we obtain an equity premium relative to bonds of $3.14 \%$, with a standard deviation of $23.8 \% .23$ The conditional survival probabilities $\left(p_{a}\right)$ are obtained from the Population Tables of Statistics Norway. ${ }^{24}$

The last five parameters in Table $\mathbb{\mathbb { V }}$ are estimated from our data set. The age profile and the variances of permanent $\left(\sigma_{p}^{2}\right)$ and transitory $\left(\sigma_{t}^{2}\right)$ shocks to labor income are obtained by applying to our measure of disposable household labor income the decomposition used by Carroll (1997) and Cocco, Gomes, and Maenhout (2005) (see Appendix $\mathrm{A}$ for details). ${ }^{2.5}$ Our estimates of the variances of labor income shocks are very close to those obtained by Blundell, Graber, and Mogstad (2015), who use the same data source but a different methodology.

The replacement rate $\phi_{r e t}$ is pinned down by computing the ratio of mean pension income five years after retirement to mean labor income five years prior to retirement. The age profile of labor income is obtained from the fitted age polynomial for the full population as documented in Table A.II.

For the purpose of our simulations, we fit a Pareto distribution to the financial wealth distribu-

\footnotetext{
${ }^{23}$ For details on the derivation of the risk-free rate and the risk premium, see Internet Appendix Section II.

${ }^{24}$ See Table 5 "Life tables" 2010 Statistics Norway.

${ }^{25}$ In Table [V, we report the variances of permanent and transitory shocks to labor income for the full population. Appendix $\mathbb{A}$ reports the estimates by education group.
} 
tion of households aged 25 and obtain an estimate of the shape $\mu_{x_{0}}$ and scale $\sigma_{x_{0}}$ parameters. We randomly draw from this distribution the initial wealth of households when we simulate the model.

In the event of a disaster a household retains only a fraction of his portfolio invested in stocks. We set the return in the event of a disaster $r_{\text {tail }}$ to -0.485 , the average return observed for investors in the 2008 stock market crash, which is the only disaster event in our detailed portfolio data. Further evidence on stock market crashes in Norway is given in the following subsection to provide guidance on the value of the probability $p_{t a i l}$ when we simulate the model and to help us judge the reasonableness of this parameter when we estimate it in Section IV.C.

- Table $\mathbb{\nabla}$ here -

The remaining parameters, namely, the discount factor $(\beta)$, the risk aversion parameter $(\gamma)$, and the participation cost $(q)$, are parameterized to standard values in the literature to illustrate the key mechanisms of the model. ${ }^{26]}$ In Section $\mathbb{L V . C}$ we estimate these parameters as well as the tail event probability $p_{\text {tail }}$.

\section{F. Stock Market Crashes in Norway}

Between 1920 and 2010, there were seven medium/large stock market crashes in Norway, with drops in the Oslo Stock Exchange index between around $25 \%$ and $50 \%$, and five large crashes if we only consider drops in the index of at least $30 \% .{ }^{27}$ Depending on the definition, this amounts to roughly one stock market crash every 13 to 23 years, implying that a household that owns stocks can experience several large losses in its stock portfolio over the life-cycle. As we document in Appendix $\mathbf{O}$ (Table C.I), $48 \%$ of the households in our sample have directly experienced five medium/large (drop in the index $\geq 25 \%$ ) stock market crashes over their life-cycle and $87 \%$ have been exposed to at least three crashes. The average number of medium/large crashes experienced over their life-cycle is 3.9 , and for large crashes $(\geq 30 \%)$ the average number is 2.2 . Depending on the age group, the fraction of medium/large crashes experienced over a Norwegian's expected lifetime (82 years) ranges between $1.2 \%$ and $3.2 \%$, while the fraction of large crashes is between $0.6 \%$ for the very young and $1.6 \%$ for the older cohorts. Hence, a reasonable value for the tail event probability should be between $0.6 \%$ and $3.2 \%$. In the simulations below, for illustrative purposes we set $p_{\text {tail }}=2 \%$, which is about the midpoint of this range. In Section $\mathbb{D} . \mathbf{G}$, we estimate this probability.

To gauge the size of the loss for the average household in the case of a tail event, we use data on single stock investments available since 2006 to compute the returns on each household's risky portfolio. Focusing on the 2008 collapse, we find that virtually all households lose on their risky portfolio. The median household loss is $47.8 \%$ and the average loss is $48.5 \%$ (somewhat less than

\footnotetext{
${ }^{26}$ In particular, we set $\beta=0.96, \gamma=10$ (as in Cocco, Gomes, and Maenhout (2005)), $q=0.3$, which amounts to USD 300 in 1995 prices, and $p_{\text {tail }}=0.02$. To facilitate comparison with the literature, we use the model without a bequest motive.

${ }^{27}$ These figures are very similar when combining the Oslo Stock Exchange and MSCI World Index as discussed in Internet Appendix Section I, except for the crisis of 1998 when the combined index fell by about $20 \%$.
} 
the drop in the Oslo Stock Exchange index of 54\%; see Appendix C, Table C.II). Accordingly, we set the return in the event of a disaster $r_{\text {tail }}$ to -0.485 .

It is important for our argument that crashes in the stock market are not accompanied by large losses on bonds. We find that this is indeed the case in Norway as we show in the Internet Appendix. Rates of return on three-, five-, and 10-year government bonds (as well as on an average bond index stretching back to the beginning of the 20th century) in crash years do not seem to show anomalous behavior. Large negative returns on bonds do not coincide with stock market crashes. During the first crash (1920), returns on bonds are actually high. They are only negative around the crashes of 1974 and 1977, but show no particular pattern around the last three crashes. Formal regressions of returns on current crash-year dummies show that the latter have no systematic explanatory power. Adding one-year lags and leads in crash-year dummies does not change the results (see Internet Appendix Figure IA.1 and Tables IA.I and IA.II). ${ }^{2.8}$

\section{Results}

This section provides the solution to the model and gives the economic intuition behind households' decision rules. To facilitate comparison with the literature, our analysis builds on Cocco, Gomes, and Maenhout (2005) and shows how the introduction of the per-period participation cost and the probability of a tail event help explain the stylized facts outlined in Section $\mathbb{~}$. This benchmark model has no bequest motive.

\section{A. Policy Functions}

The four panels of Figure 8 plot the optimal risky share of financial wealth, conditional on participating in the stock market, as a function of financial wealth at a given age. Each panel plots the optimal risky shares for three versions of the model without bequest motive: 1) the Cocco, Gomes, and Maenhout (2005) model parameterized to Norwegian data, 2) the same model augmented by a fixed per-period participation cost, and 3) the full model as described in Section 미, with a participation decision and a probability of a large stock market loss.

In all cases, the optimal portfolio rule is decreasing with both financial wealth and age, a pattern that is consistent with the literature (among others, Merton (1971)). The key driver is the importance of human capital (discounted stream of future labor income) relative to accumulated wealth. During working age, since shocks to labor income are uncorrelated with stock market returns, the deterministic component of labor income mimics the payoff of a risk-free asset. For a given level of human wealth, households with low levels of financial wealth have a relatively large amount of future income from risk-free assets (relative to their financial wealth) and thus invest

\footnotetext{
${ }^{28}$ A similar conclusion holds for real wage growth, whose dynamics does not seem to be different in crash years except after the 1977 crash, which is followed by negative wage growth (see Internet Appendix Figure IA.2 and Table IA.III). But the large negative wage growth realizations are in non-crash years. Instead, and not surprising, some of the crash years are years of deep recessions, as shown in Figure IA.3 and Table IA.IV in the Internet Appendix. In particular, the 1921 and 1977 stock market crashes are followed by deep and protracted recessions.
} 
more aggressively in stocks than wealthier households. A higher level of financial wealth reduces the relative importance of the bond-like human wealth, leading households to rebalance their financial portfolio by investing less in stocks relative to their financial wealth.

As for the negative correlation with age, this follows from the same logic. The portfolio rule is less aggressive when agents grow older, because the capitalized value of labor income drops with age, and households compensate for this drop in bond-like wealth by reducing their relative holding of risky financial assets.

\section{- Figure 8 here -}

The inclusion of a per-period participation cost introduces a wealth-participation threshold (Figure 9). ${ }^{\sqrt{9}}$ The wealth threshold of participation is mildly U-shaped with respect to age. The main drivers behind the U-shaped pattern of the participation threshold are the hump-shaped labor income process and the rebalancing channel (young households seeking to hold equity more aggressively than older households). At very early working age, holdings of accumulated assets are low, which limits the benefit of participating (grabbing the equity premium) below the per-period cost. High human wealth and greater financial wealth later on imply a higher optimal risky share, which makes stock market participation more worthwhile, and hence leads to a decrease in the age-dependent wealth threshold, which remains low for a long time. As age increases, and human wealth falls, so does the optimal risky share. Together, these two facts make participation less worthwhile for old households and thus increase the wealth threshold of participation.

\section{- Figure 9 here -}

The introduction of the disaster probability has three distinct effects. First, from Figure 8 it can be seen that for a given level of cash on hand, the disaster probability has a somewhat stronger effect on the optimal risky share of younger households relative to older households. This asymmetry arises because the high level of human wealth relative to financial wealth among younger households increases their optimal risky share above that of older households, meaning that they have more to lose from a disaster event, and they respond to the introduction of tail risk with a stronger reduction in their optimal risky share than do older households. Second, the disaster probability makes stock market participation less attractive by reducing the expected return from holding stocks, which explains why the wealth threshold of participation is higher at all ages than the threshold from the model with participation cost only (see Figure 9). Third, as clearly shown in both Figure 8 and Figure 9 , the interaction between the participation cost and the tail event probability in discouraging participation is strikingly stronger for older households than for younger ones. The interaction between the disaster event and the participation cost of stock market participation is well understood in the stylized model presented in Guiso, Sapienza, and Zingales (2008). However, its age-dependent aspect, presented here, is novel. This asymmetry is driven by

\footnotetext{
${ }^{29}$ The participation thresholds can also be seen in Figure 8, where they are the vertical cutoff lines of the conditional risky share policy functions.
} 
two facts. First, because retired households rely heavily on accumulated assets to finance their consumption, a disaster event would hurt them substantially more than young households. Second, retired households choose a substantially lower optimal risky share, implying that they need to invest substantially more than young households to benefit from the equity premium and cover the participation cost.

Overall, the policy functions show that the fixed per-period participation cost can induce stock market entry and exit over the life-cycle, leaving the conditional risky share unaffected, whereas the tail event probability has an impact on both the average behavior of the participation margin and the conditional risky share. These differential responses of the risky share and participation ease the identification of the disaster probability and the participation cost when we estimate them in Section ㅍ. O.

\section{B. Simulations}

To highlight the role of per-period participation costs and the disaster probability for the age profiles of participation and the conditional risky share, Figure 10 plots the average stock market participation rate (upper-left panel) and the average conditional risky share (lower-left panel) of simulated panels of 10,000 households from three models (without bequest motive): the Cocco, Gomes, and Maenhout (2005) model calibrated to Norwegian data, the same model with a perperiod fixed stock market participation cost without tail risk, and the same model with both endogenous participation and tail event risk.

A number of interesting features emerge from the top-left panel of Figure 10. First, as expected, in the absence of participation costs, the participation rate is $100 \%$, meaning that all households hold stocks at all ages. Second, introducing a fixed per-period participation cost generates limited participation. This effect is marked among the young because of their low levels of cash on hand. The per-period cost also generates exit among the elderly, giving rise to a hump-shaped participation profile. However, for the assumed level of participation cost (USD 300, as estimated for the U.S. by Vissing-.. $\varnothing$ rgensen (2002)), the hump in participation is much less pronounced and exit from the market takes place at a much later age than observed in the data. This property does not change even if we double the participation cost, suggesting that a reasonable participation cost is not sufficient to produce exit at the time and rate that we observe. Third, when we also add the small disaster probability, the simulated profile shows more rapid exit, which starts a few years after retirement - a feature that is consistent with the data - while leaving the pattern of participation among the young barely affected, only delaying it a bit. This is because the disaster probability affects the participation rate of old households substantially more than that of younger households, a reflection of the age dependence of the participation threshold depicted in Figure 9 and discussed in the previous subsection. Intuitively, individuals whose future consumption depends heavily on accumulated assets - the elderly - are particularly sensitive to the tail risk. This is reflected in

a higher wealth threshold for stock market participation as age increases (Figure 9), generating anticipated exit among the elderly upon the introduction of the tail event. The tail event also 
delays entry among the young, but, because their future consumption depends largely on human wealth and only marginally on accumulated assets, the effect is very small.

- Figure 1010 here -

The lower-left panel of Figure 10 plots the average conditional risky share of the simulated panel by age. Three features are worth highlighting. First, adding participation costs to the Cocco, Gomes, and Maenhout (2005) model has little effect on the level of the conditional risky share or its age profile. The risky share is very (and unrealistically) high - hitting 100\% - at a relatively young age, but households start rebalancing gradually until retirement. Second, introducing the small tail event probability lowers the conditional risky share at all ages except very early in life, when the stock of human wealth is so high that households are borrowing-constrained. On the other hand, the rebalancing pattern as households approach retirement is unchanged. Third, as in the data, rebalancing of the risky share starts long before households start exiting the stock market.

The right panel of Figure 10 plots the average accumulated financial wealth of the simulated panel over households' life-cycle. The introduction of the disaster probability lowers the average accumulated wealth at all ages relative to the Cocco, Gomes, and Maenhout (2005) model. In fact,

given the modified return structure of the risky asset, households tilt their financial wealth toward the safe asset (at all ages), as depicted in the policy functions. As a result, the average return on their financial wealth is lower, which lowers the average accumulated wealth over the life-cycle.

Looking jointly at the simulated life-cycle profile of participation and of the conditional risky share reveals that, with one exception, the participation cost and the small tail event probability can together reproduce qualitatively the pattern and timing of portfolio adjustment along the intensive and extensive margins documented in Section $\mathbb{L l}$. The exception is that, while the conditional risky share at the beginning of the life-cycle is flat in the data (see Figure 5), it is increasing in the model. However, the model replicates well the joint pattern of life-cycle rebalancing and exit. A key finding in the Norwegian data is that households start reducing the conditional risky share before retirement, and then, after retirement, begin exiting the stock market. This qualitative ability of the model to reproduce the empirical timing of the double adjustment is the main contribution of this section of the paper. We now move on to assessing the ability of our model to quantitatively reproduce the empirical patterns identified in Section 미.

\section{Estimation}

We now discuss the structural estimations. The preference parameters, namely, risk aversion, the discount factor, the participation cost, and the probability of a tail event are estimated (denoted by vector $\kappa$ ) using the method of simulated moments as outlined below:

$$
\hat{\kappa}=\arg \min \left[(\Theta(\kappa)-\mu)^{\prime} I(\Theta(\kappa)-\mu)\right],
$$

where $I$ denotes the weighting matrix, $\Theta(\kappa)$ the model moments, and $\mu$ the moments from our 
empirical model (Section एटC). ${ }^{30}$ In our first and second estimations, we estimate parameters that allow the model without a bequest motive (presented in Section $\mathbb{U}$ ) to best match the life-cycle profile of stock market participation and the conditional risky share (estimated in Section एD). In this exercise, we do not target the age-wealth profile because, contrary to the data (see Figure 7), this model generates substantial wealth decumulation after retirement (Figure 10). In our third estimation we estimate parameters that best match households' average investment behavior over the life-cycle (the extensive and intensive margins) as well as households' average age profile of financial wealth using the model with bequest motive outlined in Section $\mathbb{W D}$. This model predicts slower wealth decumulation and thus has a better chance of matching the observed financial wealth profile.

\section{C.1. Portfolio Choice}

The first estimation identifies the set of parameters $\kappa=\left[\beta, \gamma, q, p_{\text {tail }}\right]$ that allows the model to best match the conditional risky share and the participation rate over the life-cycle, $\Theta_{D}=\left[\alpha_{a}, \mathbf{1}_{a}\right]$.

- Table $\nabla$ here -

Table $\nabla$ summarizes our findings. Estimations 1 and 2 correspond to the standard model without a bequest motive. Estimation 3 corresponds to the model with a bequest motive that also targets the financial wealth profile. Not surprisingly given the size of our sample, estimated standard errors (reported in parentheses) of the model parameters are quite small. ${ }^{\mathbf{W}}$ To better appreciate the role played by the tail event, in Estimation 1 we switch off the disaster event $\left(p_{\text {tail }}\right.$ $=0$ ). We subsequently estimate it in Estimations 2 and 3. Our point estimate for the probability of the tail event is $1.1 \%$ in Estimation 2 and $1 \%$ in Estimation 3, which means that over their lifetime, households expect to experience between one and two tail risk events. These estimates are remarkably close to those implied by the frequency of historical stock market crashes in Norway discussed in Section [I.F. ${ }^{[32}$

Table $\nabla$ tells us that a relatively low disaster probability substantially enhances the model's quantitative performance. Compared to Estimation 1, Estimation 2 shows a loss function that is $24 \%$ lower. More importantly, comparing Estimations 1 and 2 clearly shows that not constraining the disaster probability to zero allows us to obtain more moderate estimates of the degree of risk aversion and a much lower participation cost. When we let $p_{\text {tail }}$ take the estimated value of $1.1 \%$, instead of forcing $p_{\text {tail }}=0$, the estimated relative risk aversion drops from 14.4 to around 11.5, a value that is more in line with the literature (for instance, Cocco, Gomes, and Maenhout (2005)

\footnotetext{
${ }^{30}$ Details on the estimation can be found in Internet Appendix Section IV.

${ }^{31}$ Standard errors of the model parameters are obtained by computing the variance covariance matrix based on random draws of 5,000 samples of the same size as our empirical data (164,015 households) from the model-based data. The very large sample size as well as the small standard errors of the targeted empirical moments (the age dummies of the risky share and participation profiles) explain the tiny estimated standard errors of the model parameters. See Internet Appendix Section IV for details.

${ }^{32}$ Barro (2006) pools historical data for 35 countries and defines a macroeconomic disaster as a decrease in GDP of at least $15 \%$ in a year; he estimates a disaster probability of $1.75 \%$.
} 
use a $\gamma$ of 10). And the participation cost drops from USD 344 to USD 109 per year (at 1995 prices), which agrees with recent evidence about the effects of wealth increases on stock market participation. 3

To further appreciate the importance of not constraining the tail event probability to zero, Figure 11 contrasts the model-generated age profiles using the estimated parameters in Estimations 1 and 2 and the data-estimated profiles. In both cases the model-simulated profiles approximate our stylized facts well, at least qualitatively. In particular, they closely reproduce the hump-shaped pattern of the participation rate and capture the differential timing when people start rebalancing the risky share and exiting the stock market. Yet estimates obtained without constraining the tail event probability to zero produce simulated life-cycle profiles with two important features: first, the timing of exit from the stock market in the simulated profile is in line with that in the data, and second, the conditional risky share is considerably lower at all ages while preserving significant rebalancing. 3

- Figure 111 here -

On the other hand, the estimate of the other preference parameter, the discount rate, is little affected. Our estimate of the discount rate is around 0.8 , which is much lower than the values typically used in calibrations of life-cycle consumption portfolio models but not at odds with models of buffer stock savings such as Deaton (1991) that focus, like us, on the accumulation of liquid assets. In these models, consumers facing idiosyncratic labor income risk and liquidity constraints accumulate precautionary savings to buffer income shocks. Impatience is necessary to limit the accumulation of liquid assets and make liquidity constraints relevant. In our case, a high discount rate is necessary to limit asset accumulation and, through this channel, discourage (costly) stock market participation. This fits well with our focus on the accumulation of financial wealth in Section $\mathbb{L}$.D.

In sum, from our first set of structural estimations, we learn that to square jointly the intensive and extensive margins of portfolio choice over the life-cycle, the best parameter combination entails a low per-period participation cost to generate entry/exit dynamics, a low discount factor to limit liquid asset accumulation and discourage participation, a relatively high risk aversion parameter to match the observed conditional risky share, and a small disaster probability to match the timing of exit from the stock market and the level of the conditional risky share, particularly at young ages.

\footnotetext{
${ }^{33}$ Briggs et al. (2015) try to identify the causal effect of wealth on stock market participation using large random assignments of lottery wins in Sweden. They find effects that are inconsistent with the relatively high values of participation costs in the literature. In a calibration exercise they show that a combination of low participation costs and pessimistic beliefs about stock market returns can explain the observed empirical responses. This conclusion parallels ours: a low participation cost combined with a small probability of a large loss can better explain limited participation. As we notice below, our model highlights that tail event beliefs are important not only to rationalize limited participation, but also to account for the timing of participation over the life-cycle, as well as to limit the puzzlingly high share in stocks at young age.

${ }^{34}$ Notice that the effect of the tail event on the timing of exit cannot be inferred from the simulated profiles underlying Estimations 1 and 2 in Figure 10 because the whole set of parameters, not just the disaster probability, changes.
} 
These conclusions, however, are obtained in attempting to match the life-cycle participation and asset allocation profiles without also attempting to match the wealth accumulation profile. In the following section, we aim to explain these three dimensions jointly. Before moving on, we stress the value of the tail event by noticing that taking it into account greatly improves the model performance when we look at a moment that we do not target explicitly. As the last row of Table $\nabla$ shows, the average wealth/income ratio at age 65 is estimated at 3.76 when the tail event probability is constrained at zero. This is more than twice the value observed in the data (1.62), but it gets close to this value in Estimations 2 and 3, which both allow for the tail event.

\section{C.2. Extensive Margin, Intensive Margin, and Financial Wealth}

We estimate a set of parameters $\kappa=\left[\gamma, \beta, q, p_{\text {tail }}\right]$ that enables the model with a bequest motive (see Section ए.DD), which we fix at $b=0.5$, to match both the investment behavior (conditional risky share and participation rate over the life-cycle) and the average financial wealth accumulated over the life-cycle $\Theta_{D}=\left[\alpha_{a}, \mathbf{1}_{a}, x_{a}\right]$.

The third column of Table $\nabla$ summarizes the findings of our structural estimations. A comparison of the two sets of estimates (Estimations 2 and 3) reveals that introducing a bequest motive brings the estimated risk aversion parameter down to 11, which is even closer to the values used in prior literature. Indeed, with a bequest motive, observed asset accumulation can be matched with a weaker precautionary motive and thus a lower risk aversion (and prudence). There is no effect on the discount rate, while the estimated tail probability - $1 \%$ - is only slightly lower than in Estimation 2. Interestingly, an even lower participation cost (USD 65 instead of USD 109) is enough to match the participation pattern. In sum, targeting the wealth profile together with the participation and portfolio profiles delivers more realistic parameter estimates.

- Figure 12 here -

Figure 12 shows the model-generated and empirical profiles using the parameters in Estimation 3. A number of features are worth noting. First, the model with bequest well tracks the financial wealth profile until retirement, but even this model predicts more asset decumulation at old age than observed in the data (bottom panel). Second, as shown in the first two panels, even when we target the financial wealth profile, the model is able to reproduce the salient features of the age participation profile and the conditional risky share that we observe in the data. The age participation profile is hump-shaped and exit starts around retirement. Furthermore, compared to Estimation 2, the model profile is closer to the empirical profile. Third, the conditional risky share profile shows substantial rebalancing starting earlier in life and a level of the risky share that is not far from that observed in the data. Compared to Estimation 2, rebalancing starts later and the risky share has a more pronounced hump shape than in the data.

Overall, both the models with and without bequest are able to capture the basic features of the portfolio profile. However, both models generate too little participation in the stock market at an early age and too fast an exit later in life compared to what we observe in the data. In 
addition, the model features lower risky shares in stocks among younger participants than seen in the data. Thus, though our estimated models perform well in matching the broad pattern of the timing of rebalancing and participation over the life-cycle and of liquid asset accumulation, they are still probably too stylized to fit the data more closely.

\section{Conclusion}

Over the past decade, many scholars have used calibrated models to study life-cycle portfolio allocations, departing from the simplifying assumptions of early generations models and adding realistic features to households' environments, including uninsurable income risk, nontradeable human capital, and borrowing constraints. Despite these (and other) complications, these models uniformly predict that households should start lowering exposure to the stock market before retirement in order to compensate for the decline in their stock of human wealth as households age, which in this model mostly acts as a risk-free asset. Finding empirical evidence in support of such rebalancing, however, has been difficult. We argue that this is likely due to data limitations, both because a proper treatment of the issue requires long longitudinal data and because information on assets needs to be exhaustive and free of measurement error. Combining administrative and tax registry data from Norway, we fulfill these requirements and find that households do indeed manage their portfolio over the life-cycle in a way that is consistent with model predictions. In particular, we find that households adjust their financial portfolios along two margins: the share invested if they participate in the stock market and the decision of whether to stay or leave the market. Households tend to enter the stock market early in life as they accumulate assets and tend to invest a relatively large share of financial wealth in stocks. As they start getting closer to retirement, they rebalance their portfolio share, reducing it gradually. Around retirement they start adjusting on the other margin by exiting the stock market. This double adjustment pattern along the intensive and extensive margins with its clear timing cannot be explained by any of the available life-cycle portfolio models. However, an extension of these models that incorporates a small per-period participation cost and a small probability of a large loss when investing in stocks is able not only to generate the double pattern of adjustment, but also to replicate the profiles of stock market participation and portfolio shares observed in the data. While specific features of our findings may depend on Norwegian households being little exposed to some sources of tail risk, such as health and job-loss risk, the general pattern of our results hinges on stock market crashes, a tail risk that is shared by all economies.

Initial submission: [DATE]; Accepted: [DATE CONDITIONALLY ACCEPTED]

Editors: Bruno Biais, Michael R. Roberts, and Kenneth J. Singleton [OR ACTING EDITOR] 


\section{Appendix A. Earnings Variances and Human Wealth}

To estimate the variance of permanent and transitory shocks to labor income and the value of a household's human wealth, we rely on a broad measure of household labor income obtained from tax records by summing the labor income of the two spouses for all households in our portfolio sample. The income data cover the same time span over which we observe the household's portfolio. As in Carroll (1997), we define labor income as the sum of after-tax earnings at the household level. Besides earnings, it includes capital income and transfers (including sickness benefits, compensation for maternity leave, benefits paid during unemployment spells, and pensions). Values are in 1995 USD converted using the 1995 NOK/USD exchange rate. The statutory retirement age in Norway is 67 , although in practice a number of arrangements enable workers to retire earlier. ${ }^{3.5}$ Our measure is deflated using the growth in the National Insurance Scheme basic amount, which is used to adjust payments of unemployment insurance and pensions. 36

\section{A. Variance of Permanent and Transitory Shocks to Labor Income}

Following Carroll (1997) and Cocco, Gomes, and Maenhout (2005), we estimate the following model for $(\log )$ labor income, $Y_{i, a, t}$, for household $i$ aged $a$ at time $t$ :

$$
\log \left(Y_{i, a, t}\right)=\alpha+\beta\left(X_{i, a, t}\right)+\theta_{a}+\gamma_{t}+\varepsilon_{i, a, t}
$$

where $\alpha$ is a constant, $X_{i, a, t}$ is a set of demographic controls (such as household size), $\theta_{a}$ is a full set of age dummies, $\gamma_{t}$ denotes calendar year fixed effects, and $\varepsilon_{i, a, t}$ denotes the error term, which captures shocks to labor income. We estimate the model separately for three levels of household educational attainment (using the husband's education), as well as for the full sample of nonretired households. ${ }^{37}$

To estimate the variance components of the income process, we follow the procedure in Carroll and Samwick (1997) and Cocco, Gomes, and Maenhout (2005) and assume that labor income innovations can be decomposed into a permanent and a transitory shock component, with variances $\sigma_{u}^{2}$ and $\sigma_{\eta}^{2}$, respectively. Using the estimated model we compute for each observation prediction errors $d$ years ahead, denoted $\widehat{\varepsilon}_{i d}$, for various $d$ starting from the base year (1995). Then, noting that $\operatorname{var}\left(\widehat{\varepsilon}_{i d}\right)=d \sigma_{u}^{2}+2 \sigma_{\eta}^{2}$, we retrieve the two variances from an OLS regression of $\operatorname{var}\left(r_{i d}\right)$ on $d$ and a constant term. The estimates are shown in Table A.ll. The variance of transitory shocks is larger than that of permanent shocks for all education groups as well as the full sample, with some differences in its extent. We do not find large differences in the size of the variances across

\footnotetext{
${ }^{35}$ In Norway, the actual average retirement age is around 64. See, for example, http://ec.europa.eu/economy_finance/publications/publication14992_en.pdf. Early retirement schemes are widespread in Norway and workers may be eligible for these from the age of 62. See, for example, Vestad (2013).

${ }^{36}$ See The Norwegian Labour and Welfare Administration, http://www.nav.no/English/Membership+in+The+National+Insurance+Scheme, for more information on the basic amount, "grunnbeløpet."

${ }^{37}$ We cut the sample at the age of 65 to avoid variation in income due to early retirement from influencing our results.
} 
education groups, with a tendency for households with a high school education to face lower labor income uncertainty than households with less than high school education or households with a college degree. Compared to Cocco, Gomes, and Maenhout (200.5), we find much lower values of the transitory components. ${ }^{38}$ There are two possible explanations for this difference. The first is that workers in Norway are covered by a generous social insurance scheme that reduces labor income effects of temporary shocks. The second is that, unlike Cocco, Gomes, and Maenhout (2005), who use PSID surveys, we use administrative records, and there is much less scope for measurement errors that might inflate the estimated variance of transitory shocks.

- Table A.] here -

In contrast, our estimates of the variance of permanent and transitory shocks are very close to those of Blundell, Graber, and Mogstad (2015), which are based on the same Norwegian data that we use but are obtained using a different methodology and exclude income from self employment. Unlike us, they allow for age-varying variances and find that the earnings variances follow a Ushaped profile. Variances are higher at the very beginning of the (working) life-cycle (particularly for workers with high education) and essentially are age-invariant for many years before retirement, when they increase again. Our estimates are similar to theirs for middle-aged households.

Finally, we also compute the correlation between labor income and stock market returns on the Norwegian stock market. A negative correlation would represent a hedging opportunity for households, as argued in Bodie, Merton, and Samuelson (1992). Table All shows that the correlation tends to be positive but very small and never statistically significant. This is in line with the results in Cocco, Gomes, and Maenhout (2005) for the U.S. 39

\section{B. Human Wealth}

To obtain an estimate of the human wealth of a household of age $a$, we estimate equation (12) on the full sample of households aged between 25 and 80 and on the three education groups separately. We then retrieve the age dummies and regress them on a fifth-order polynomial. The age effects (solid lines) and the fitted polynomials are plotted in Figure A.1. Table A.Il shows the estimated fifth-order polynomial.

- Table A.]l here -

- Figure A.] here -

\footnotetext{
${ }^{38}$ The estimates of the income variance are highly dependent on very low income realizations of a few households. In previous contributions this has been taken care of by excluding households with realized incomes below some threshold, justifying the choice with the need to limit the influence of measurement errors. Since we use highly reliable administrative records, we retain the full sample, including households with very low income realizations.

${ }^{39}$ The same holds for a combined measure of returns from the S\&P 500 and the Oslo Stock Exchange, discussed in Internet Appendix Section I.
} 
The income profiles by educational attainment are consistent with the evidence in the literature showing much steeper profiles for high-education workers. To compute lifetime wealth, we proceed as follows. Let $G_{e}(a)$ denote the estimated fifth-order polynomial in age for log income for a household with education level $e$. Assuming that all the household characteristics apart from age will not change in the future, the labor income (or pension benefits) at age $a+\tau$ of a household with education level $e$ and age $a$ can be calculated using the function $G_{e}(a)$ as follows:

$$
L_{e}(a+\tau)=L_{e}(a) \frac{\exp \left(G_{e}(a+\tau)\right)}{\exp \left(G_{e}(a)\right)}
$$

The human wealth for a household of age $a$ is then computed as

$$
H_{e, a}=L_{e}(a)+\sum_{\tau=1}^{T-a} p(a+\tau \mid a) \frac{L_{e}(a+\tau)}{(1+r)}
$$

where $p(a+\tau \mid a)$ is the probability of surviving to age $a+\tau$ conditional on survival to $a$, from the population tables of Statistics Norway, ${ }^{40}$ and $r$ is the risk-free rate, which we set to 0.02. For each household, we obtain an estimate of $H_{e, a}$ for each age of households in the sample.

\section{Appendix B. Data Treatment and Identification}

\section{A. Adjustment for Wealth-Mortality Correlation}

Following Attanasio and Hoynes (2000), we define the death of either the husband or the wife as the death of the household. Further, we split our sample in each year and age group (using the age of the husband) by wealth percentile. Using observations across years, we then estimate the probability of survival with a logit model as a function of the wealth percentile and age with interactions up to the third polynomial. We allow the polynomials to differ with age by inserting four splines in wealth, and we control for household education. We use the regression estimates to calculate the survival probability from one year to the next. We repeat this procedure for all years in our sample and compute cumulative survival probabilities for each household. Finally, we use the inverse of these probabilities to weigh the observations of our wealth regression. The relationship between survival and wealth is strongly positive in the data; hence, the wealth of poorer households that survive until old age will be weighted up. These weighted observations are plotted by cohort in Figure 四.

\section{B. Identification Restrictions}

Let $s(a)$ denote the share of financial wealth $(W(a))$ invested in risky assets by an individual aged $a$ and $H(a)$ his stock of human capital. In Merton (1971), the share of risky assets as a fraction of lifetime wealth $W(a)+H(a)$ is

\footnotetext{
${ }^{40}$ See http://ssb.no/en/dode/.
} 


$$
\frac{s(a) W(a)}{W(a)+H(a)}=\frac{r_{p}}{\gamma \sigma_{r}^{2}},
$$

where $r_{p}$ denotes the equity premium, $\sigma_{r}^{2}$ the variance of stock returns, and $\gamma$ the investor's relative risk aversion. This share is constant over age. In contrast, $s(a)=\frac{r_{p}}{\gamma \sigma_{r}^{2}}\left(1+\frac{H(a)}{W(a)}\right)$ varies over the lifecycle because the ratio of human capital to financial wealth $\frac{H(a)}{W(a)}$ varies with age. Thus, capturing $\frac{H(a)}{W(a)}$ with a set of age dummies, $s(a)$ is unaffected by the level of human wealth or the level of financial wealth.

This restriction holds true in the context of the Merton (1971) model. Whether it is still true once the assumptions on which it builds are relaxed - in particular, the market completeness assumption - is hard to tell, because there is no closed-form solution to the model. One might think that with uninsurable income risk, investors with more cash on hand would stand background risk more easily, suggesting that cash on hand can reduce the effect of background risk on the risky portfolio share, which would invalidate the exclusion restriction. To check how important this might be, we use the simulated data generated by the model in Section $\mathbb{W}$ and run regressions of the portfolio share on a full set of time dummies and cash on hand, taking endogenous participation into account. We find that cash on hand has a positive and strong effect on participation: a one-standard-deviation increase in cash on hand increases the probability of participation in the stock market by 10 percentage points - about $25 \%$ of the mean participation rate. On the other hand, it has a negative but very small effect on the share: a one-standard-deviation increase in cash on hand lowers the risky share by 1.6 percentage points, which is a tiny effect given that its mean is around $40 \%$. Thus, though the exclusion restriction does not hold literally, it seems to hold approximately. An alternative exclusion restriction implied by the theory would be to use information on per-period participation costs in the probit regression. Finding valid measures of individual participation costs is very difficult and, so far, we have not been able to come up with a convincing one. Thus, rather than use unconvincing proxies for participation costs, we choose to impose an identifying restriction that simulations suggest is, economically speaking, not far from what literal validity requires.

\section{Appendix C. Tail Risk: Stock Market Collapses in Norway}

Since 1920, the oldest substantial drop the Oslo Stock Exchange experienced in the lifetime of some of the individuals in our sample, there have been six other stock market crashes (i.e., drops in the stock market index of $25 \%$ or more), including the 2008 collapse: 1920 (34\%), 1921 (32.7\%), 1974 (34.2\%), 1977 (25.5\%), 1998 (28.9\%), 2002 (30.2\%), and 2008 (53.5\%). Hence, Norwegians have had several opportunities over their life-cycle to directly experience large losses on their stock investments. Table C.ll shows the fraction of households in our sample that over their life-cycle (above the age of 18) have experienced up to $n$ medium/large stock market drops (drops $\geqq 25 \%$ ) or large drops (drops $\geqq 30 \%$ ). We find that $48 \%$ of the households have been exposed to five 
medium/large stock market crashes and three large crashes during their lifetime, with the mean number of medium/large (large) crashes experienced equal to 3.9 (2.2). This suggests that while large drops in the stock market are indeed infrequent, the frequency, even that directly experienced by the households in the sample, is nonnegligible.

- Table C.Dl here -

To get an estimate of the loss experienced by the average household, we exploit the fact that as of 2006, for each household we know the value of every directly held stock in their portfolio and the ISIN code. Accordingly, we compute the individual returns on their risky portfolio. As we do not observe the individual mutual fund the household invests in, we approximate returns in mutual funds by weighting returns on the Oslo Stock Exchange and the MSCI World Index using information on the aggregate asset allocation of mutual funds in Norway (see Internet Appendix Section I).

Table C.Il shows the cross-sectional distribution of these returns for the one disaster year we have detailed portfolio data for, 2008. The table shows that virtually all households lose on their risky portfolio. The median loss is $47.8 \%$ and the average loss is $48.5 \%$ (a little less than the return of the Oslo Stock Exchange that year of $-54 \%$ ), which is the number we use to calibrate risky asset loss in the event of a stock market crash.

- Table C.II here - 


\section{REFERENCES}

Agnew, Julie, Pierluigi Balduzzi, and Annika Sundén, 2003, Portfolio choice and trading in a large 401(k) plan, American Economic Review 93, 193-215.

Alan, Sule, 2006, Entry costs and stock market participation over the life cycle, Review of Economic Dynamics 9, 588-611.

Alan, Sule, 2012, Do disaster expectations explain household portfolios? Quantitative Economics $3,1-28$.

Ameriks, John, and Stephen P. Zeldes, 2002, How do household portfolio shares vary with age? TIAA-CREF Working paper 112(2).

Attanasio, Orazio P., and Hilary Williamson Hoynes, 2000, Differential mortality and wealth accumulation, Journal of Human Resources 35, 1-29.

Barro, Robert J., 2006, Rare disasters and asset markets in the twentieth century, Quarterly Journal of Economics 121, 823-866.

Benzoni, Luca, Pierre Collin-Dufresne, and Robert S. Goldstein, 2007, Portfolio choice over the life-cycle when the stock and labor markets are cointegrated, Journal of Finance 62, 2123-2167.

Bernheim, B. Douglas, 1987, Dissaving after retirement: Testing the pure life cycle hypothesis, in Zvi Bodie, John Shoven, and David Wise, eds., Issues in Pension Economics (University of Chicago Press).

Blundell, Richard, Michael Graber, and Magne Mogstad, 2015, Labor income dynamics and the insurance from taxes, transfers, and the family, Journal of Public Economics 127, 58-73.

Bodie, Zvi, Robert C. Merton, and William F. Samuelson, 1992, Labor supply flexibility and portfolio choice in a life cycle model, Journal of Economic Dynamics and Control 16, 427-449.

Briggs, Joseph S., David Cesarini, Erik Lindqvist, and Robert Östling, 2015, Windfall gains and stock market participation, Working paper, NBER. 
Browning, Martin, Ian Crawford, and Marike Knoef, 2012, The age-period cohort problem: Set identification and point identification, Cemmap Working Paper.

Calvet, Laurent E., John Y. Campbell, and Paolo Sodini, 2007, Down or out: Assessing the welfare costs of household investment mistakes, Journal of Political Economy 115, 707-747.

Calvet, Laurent E., John Y. Campbell, and Paolo Sodini, 2009, Fight or flight? Portfolio rebalancing by individual investors, Quarterly Journal of Economics 124, 301-348.

Calvet, Laurent E., and Paolo Sodini, 2014, Twin picks: Disentangling the determinants of risktaking in household portfolios, Journal of Finance 69, 867-906.

Campbell, John Y., and Luis M. Viceira, 1999, Consumption and portfolio decisions when expected returns are time varying, Quarterly Journal of Economics 114, 433-495.

Campbell, John Y., and Luis M. Viceira, 2001, Who should buy long-term bonds? American Economic Review 91, 99-127.

Campbell, John Y., and Luis M. Viceira, 2002, Strategic Asset Allocation: Portfolio Choice for Long-Term Investors (Oxford University Press).

Carroll, Christopher D., 1997, Buffer-stock saving and the life cycle/permanent income hypothesis, Quarterly Journal of Economics 112, 1-55.

Carroll, Christopher D., and Andrew Samwick, 1997, The nature of precautionary wealth, Journal of Monetary Economics 40, 41-71.

Cocco, João F., 2005, Portfolio choice in the presence of housing, Review of Financial Studies 18, $535-567$.

Cocco, João F., Francisco J. Gomes, and Pascal J. Maenhout, 2005, Consumption and portfolio choice over the life cycle, Review of Financial Studies 18, 491-533.

Davis, Steven J., Felix Kubler, and Paul Willen, 2006, Borrowing costs and the demand for equity over the life cycle, Review of Economics and Statistics 88, 348-362.

Deaton, Angus, 1991, Saving and liquidity constraints, Econometrica 59, 1221-1248. 
Deaton, Angus, 1997, The Analysis of Household Surveys: A Microeconometric Approach to Development Policy (World Bank Publications).

Deaton, Angus, and Christina Paxson, 1994, Saving, growth, and aging in Taiwan, in David Wise, ed., Studies in the Economics of Aging (University of Chicago Press).

Dimson, Elroy, Paul Marsh, and Mike Staunton, 2008, The worldwide equity premium: A smaller puzzle, in Rajnish Mehra, ed., Handbook of the Equity Risk Premium (Elsevier).

Fagereng, Andreas, Luigi Guiso, and Luigi Pistaferri, 2016, Portfolio choices, firm shocks and uninsurable wage risk, Working paper.

Gakidis, Haralabos E., 1998, Portfolio Choice with Uninsurable Labor Earnings, Ph.D. thesis, MIT.

Giuliano, Paola, and Antonio Spilimbergo, 2014, Growing up in a recession: Beliefs and the macroeconomy, Review of Economic Studies 81, 787-817.

Gollier, Christian, and Richard Zeckhauser, 2002, Time horizon and portfolio risk, Journal of Risk and Uncertainty 3, 195-212.

Gomes, Francisco, Laurence J. Kotlikoff, and Luis M. Viceira, 2008, Optimal life-cycle investing with flexible labor supply: A welfare analysis of life-cycle funds, American Economic Review 98, 297-303.

Gomes, Francisco, and Alexander Michaelides, 2003, Portfolio choice with internal habit formation: A life-cycle model with uninsurable labor income risk, Review of Economic Dynamics 6, 729-766.

Gomes, Francisco, and Alexander Michaelides, 2005, Optimal life-cycle asset allocation: Understanding the empirical evidence, Journal of Finance 60, 869-904.

Guiso, Luigi, Michael Haliassos, and Tullio Jappelli, 2002, Household Portfolios (MIT Press).

Guiso, Luigi, Paola Sapienza, and Luigi Zingales, 2008, Trusting the stock market, Journal of Finance 63, 2557-2600.

Guiso, Luigi, and Paolo Sodini, 2013, Household Finance. An Emerging Field., in George M. Constantinides, Milton Harris, and Rene M. Stulz, eds., Handbook of the Economics of Finance (Elsevier Science, North Holland). 
Haliassos, Michael, and Alexander Michaelides, 2002, Calibration and computation of household portfolio models, in Luigi Guiso, Michael Haliassos, and Tullio Jappelli, eds., Household Portfolios (MIT Press).

Haliassos, Michael, and Alexander Michaelides, 2003, Portfolio choice and liquidity constraints, International Economic Review 44, 143-177.

Heaton, John, and Deborah Lucas, 1997, Market frictions, savings behavior, and portfolio choice, Macroeconomic Dynamics 1, 76-101.

Hubbard, R. Glenn, Jonathan Skinner, and Stephen P. Zeldes, 1995, Precautionary saving and social insurance, Journal of Political Economy 103, 360-399.

Jappelli, Tullio, 1999, The age-wealth profile and the life-cycle hypothesis: A cohort analysis with a time series of cross-sections of Italian households, Review of Income and Wealth 45, 57-75.

Kandel, Shmuel, and Robert F. Stambaugh, 1995, On the predictability of stock returns: An asset-allocation perspective, Journal of Finance 51, 385-424.

Kapteyn, Arie, Rob Alessie, and Annamaria Lusardi, 2005, Explaining the wealth holdings of different cohorts: Productivity growth and social security, European Economic Review 49, 13611391.

Klovland, Jan Tore, 2004, Bond markets and bond yields in Norway 1819-2003, in Øyvind Eitrheim, Jan Tore Klovland, and Jan Fredrik Qvigstad, eds., Historical Monetary Statistics for Norway 1819-2003 (Norges Bank).

Liu, Kai, Kjell Gunnar Salvanes, and Erik Ø. Sørensen, 2016, Good skills in bad times: Cyclical skill mismatch and the long-term effects of graduating in a recession, European Economic Review, $84,3-17$.

Malmendier, Ulrike, and Stefan Nagel, 2011, Depression babies: Do macroeconomic experiences affect risk taking? Quarterly Journal of Economics 126, 373-416.

Merton, Robert C., 1969, Lifetime portfolio selection under uncertainty: The continuous-time case, Review of Economics and Statistics 51, 247. 
Merton, Robert C., 1971, Optimum consumption and portfolio rules in a continuous-time model, Journal of Economic Theory 413, 373-413.

Mossin, Jan, 1968, Optimal multiperiod portfolio policies, Journal of Business 41, 215-229.

Ødegaard, Bernt Arne, 2007, Asset pricing at the Oslo Stock Exchange. A source book, Working paper, BI Norwegian School of Management.

Oreopoulos, Philip, Till von Wachter, and Andrew Heisz, 2012, The short- and long-term career effects of graduating in a recession, American Economic Journal: Applied Economics 4, 1-29.

Polkovnichenko, Valery, 2007, Life-cycle portfolio choice with additive habit formation preferences and uninsurable labor income risk, Review of Financial Studies 20, 83-124.

Rietz, Thomas A., 1988, The equity risk premium: A solution, Journal of Monetary Economics $22,117-131$.

Ringard, Ånen, Anna Sagan, Ingrid Sperre Saunes, and Anne Karin Lindahl, 2013, Norway. Health system review, Health Systems in Transition 15, 1-162.

Samuelson, Paul A., 1969, Lifetime portfolio selection by dynamic stochastic programming, Review of Economics and Statistics 51, 239-246.

Shorrocks, Anthony, 1975, The age-wealth relationship: A cross-section and cohort analysis, Review of Economics and Statistics 57, 155-163.

Storesletten, Kjetil, Christopher I. Telmer, and Amir Yaron, 2007, Asset pricing with idiosyncratic risk and overlapping generations, Review of Economic Dynamics 10, 519-548.

Vestad, Ola Lotherington, 2013, Labour supply effects of early retirement, Labour Economics 25, 98-109.

Viceira, Luis M., 2001, Optimal portfolio choice for long-horizon investors with nontradable labor income, Journal of Finance 56, 433-470.

Vissing-Jørgensen, Annette, 2002, Towards an explanation of household portfolio choice heterogeneity: Nonfinancial income and participation cost structures, Working paper, NBER. 
Yang, Yang, Wenjiang J. Fu, and Kenneth C. Land, 2004, A methodological comparison of ageperiod-cohort models: The intrinsic estimator and conventional generalized linear models, Sociological Methodology 34, 75-110.

Yang, Yang, Sam Schulhofer-Wohl, Wenjiang J. Fu, and Kenneth C. Land, 2008, The intrinsic estimator for age-period-cohort analysis: What it is and how to use it, American Journal of Sociology 113, 1697-1736.

Yogo, Motohiro, 2009, Portfolio choice in retirement: Health risk and the demand for annuities, housing, and risky assets, Working paper, NBER. 


\section{Figures and Tables}

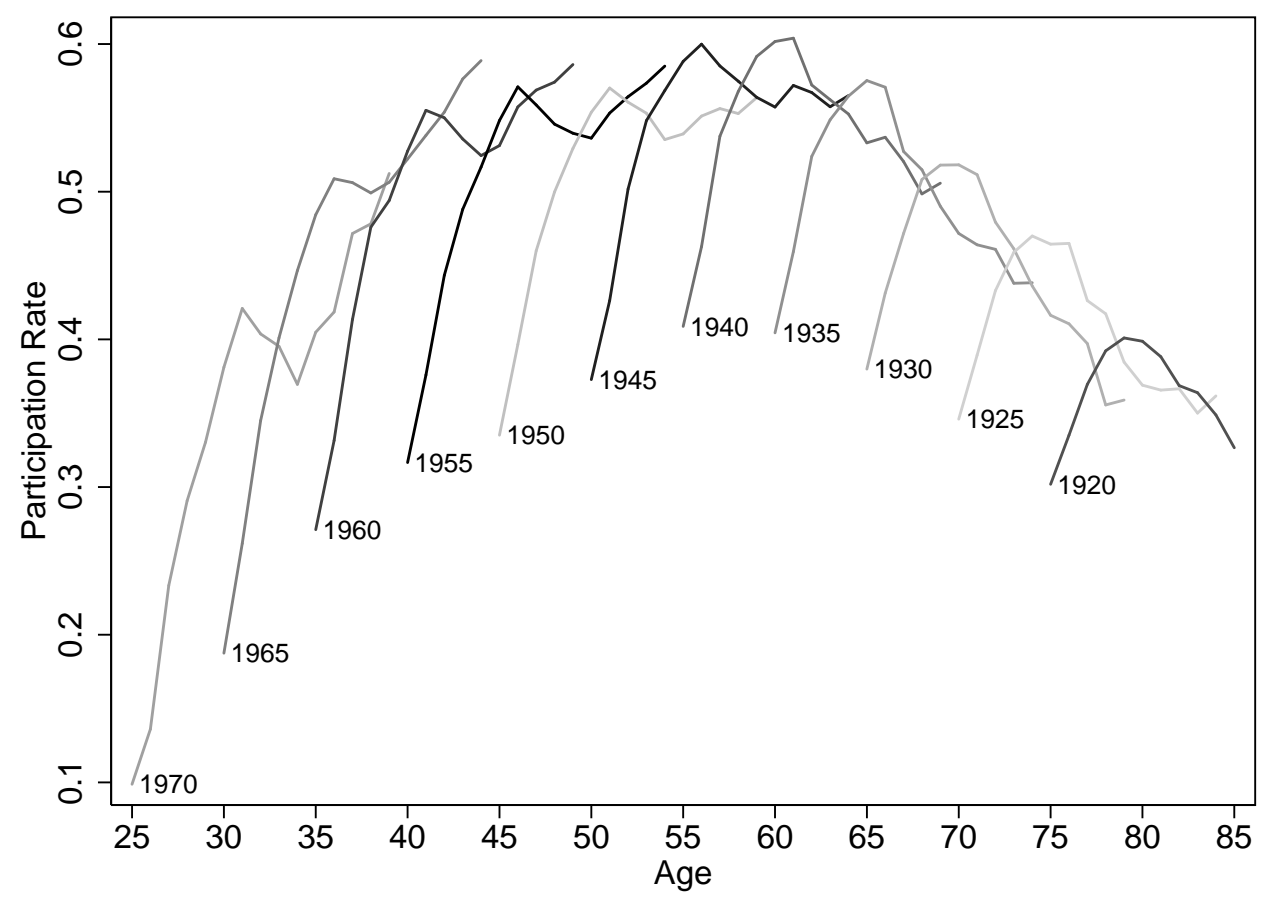

Figure 1. Participation rates in risky asset markets. This figure plots the mean participation rates in risky asset markets by age for selected cohorts over the period 1995 to 2009 .
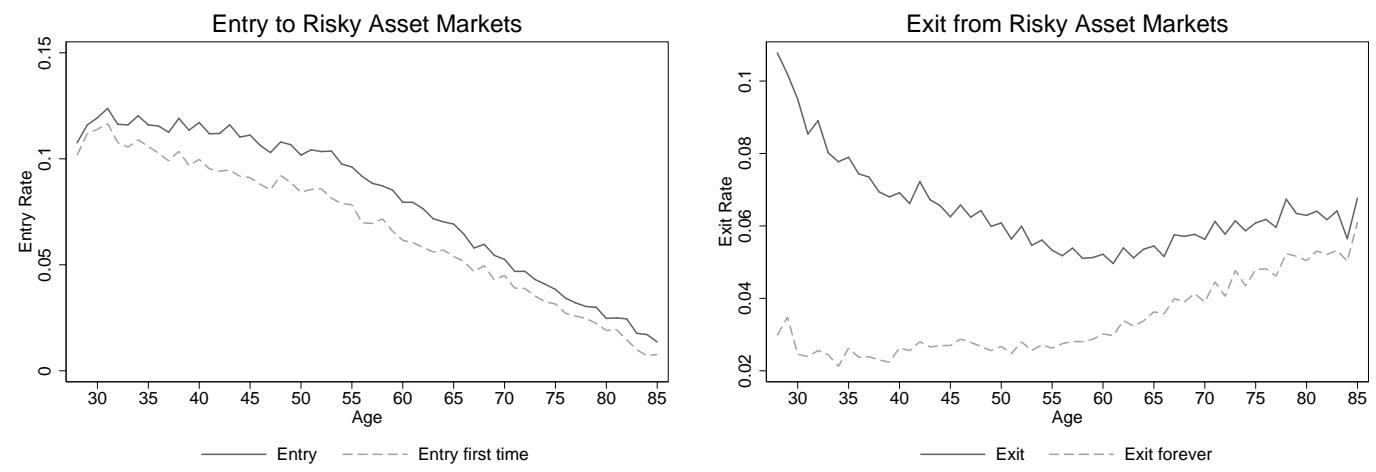

Figure 2. Entry and exit rates to/from risky asset markets. These figures plot entry and exit rates to/from risky asset markets. The left panel depicts entry and exit frequencies, allowing for reentry/exits, whereas the right panel depicts frequencies of first-time entry and once-and-for-all exits. 


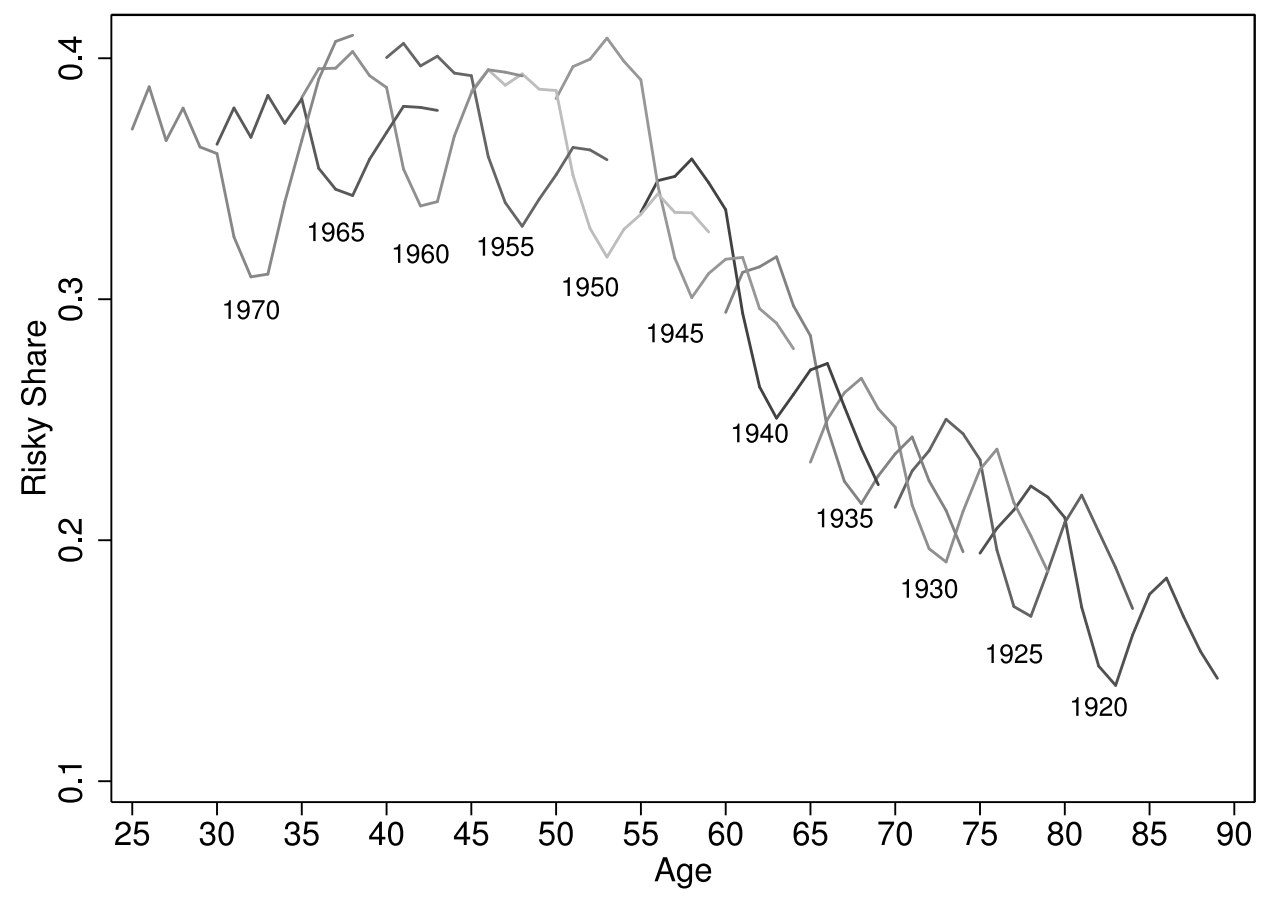

Figure 3. Risky share of financial wealth by cohort. This figure plots the average risky shares of households' financial portfolios conditional on participation, for selected cohorts by age.



Figure 4. Financial wealth by cohort. This figure plots the average financial wealth for selected cohorts by age. Values are in 1995 USD, and the wealth profiles are corrected for mortality following Attanasio and Hovnes (2000), as outlined in Appendix B. 

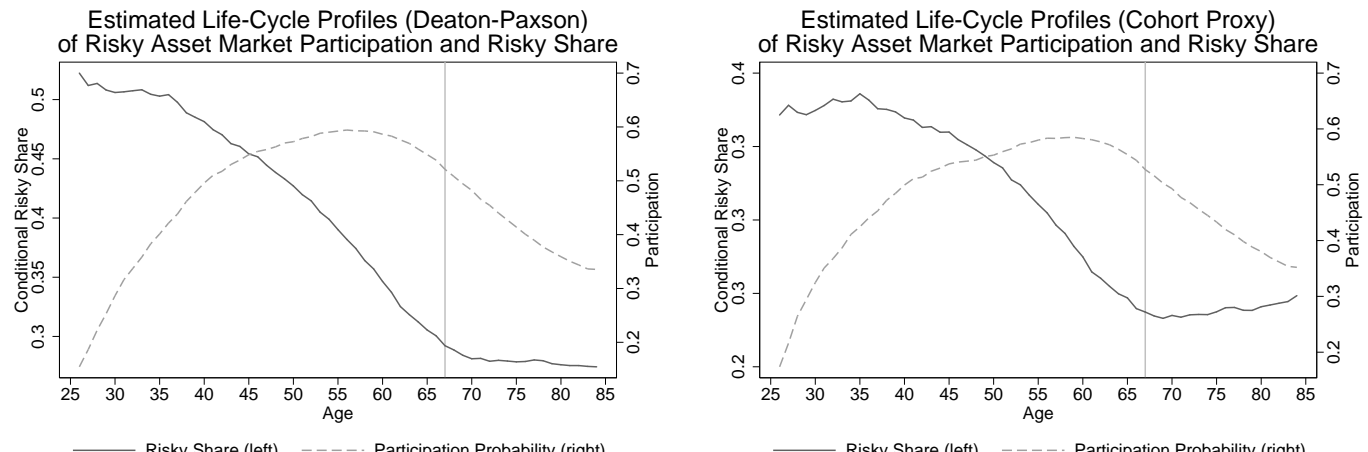

Figure 5. Estimation: risky asset market participation and risky share. The left panel in the figure plots the life-cycle patterns for both risky asset market participation and the conditional risky share of financial wealth, which are estimated using the Heckman selection equation applying the Deaton and Paxson (19.94) methodology reported in columns (1) and (2) of Table $\mathbb{W}$. The right panel applies the cohort-proxy methodology reported in columns (3) and (4) of Table $\mathbb{W}$. For the selection/participation equation, we plot the marginal values of the estimated underlying probit equation, and for the risky share, the age coefficients of the outcome equation in the Heckman model.
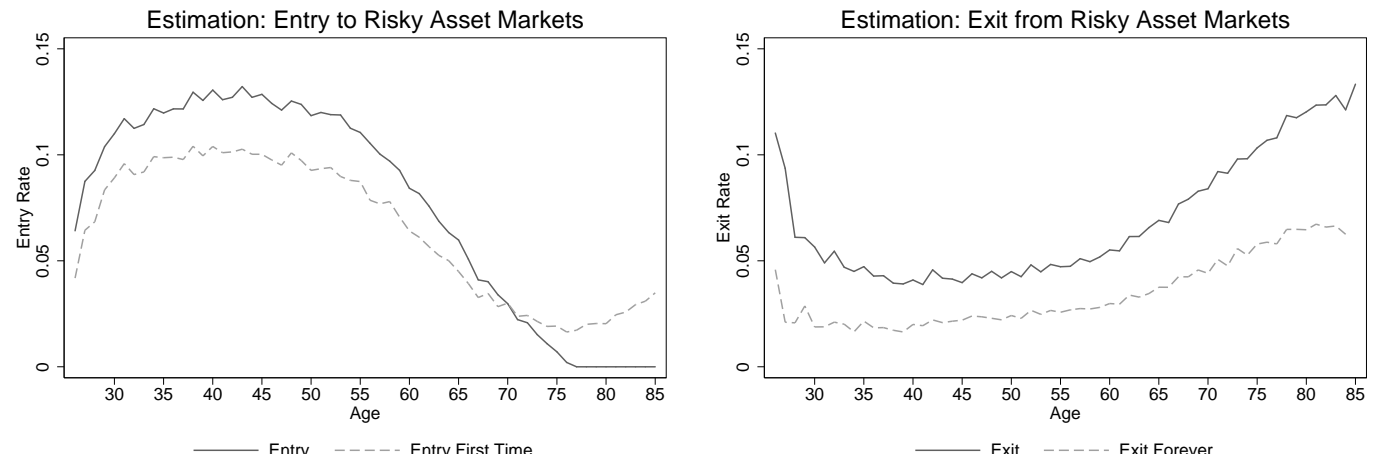

Figure 6. Life-cycle patterns of entry to and exit from risky asset markets. These figures plot the estimated life-cycle patterns of entry to and exit from risky asset markets, defined by the two sets of measures in Table $\mathbb{W}$ imposing the Deaton-Paxson (1994) restriction of zero-sum time effects (see Section ए.B). 


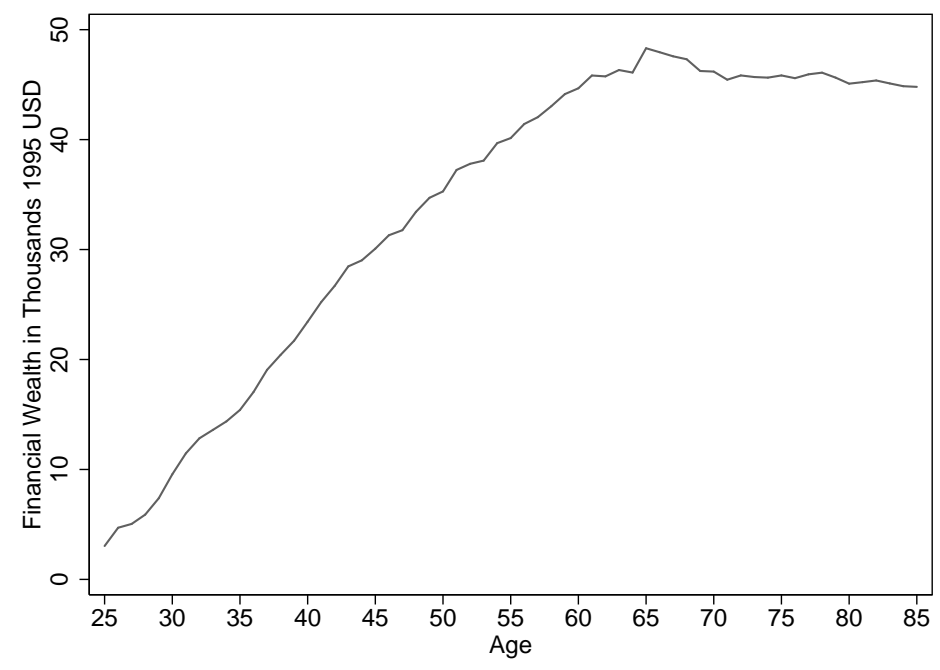

Figure 7. Life-cycle pattern of financial wealth. This figure plots the estimated life-cycle pattern of financial wealth when correcting for differences in mortality, following Attanasio and Hoynes (2000), and proxying for cohort effects with deviations from trend GDP-per-capita at early ages (Kapteyn, Alessie, and Lusardi (2005), Dappelli (1999)). Values are in 1995 USD.


Figure 8. Policy functions: conditional risky share. 


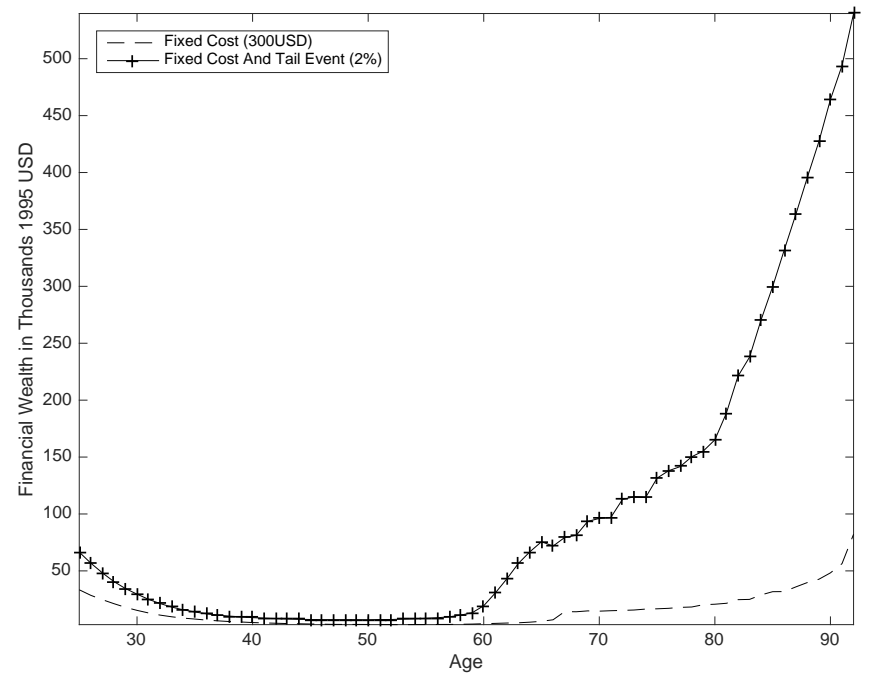

Figure 9. Wealth threshold of participation as a function of age.
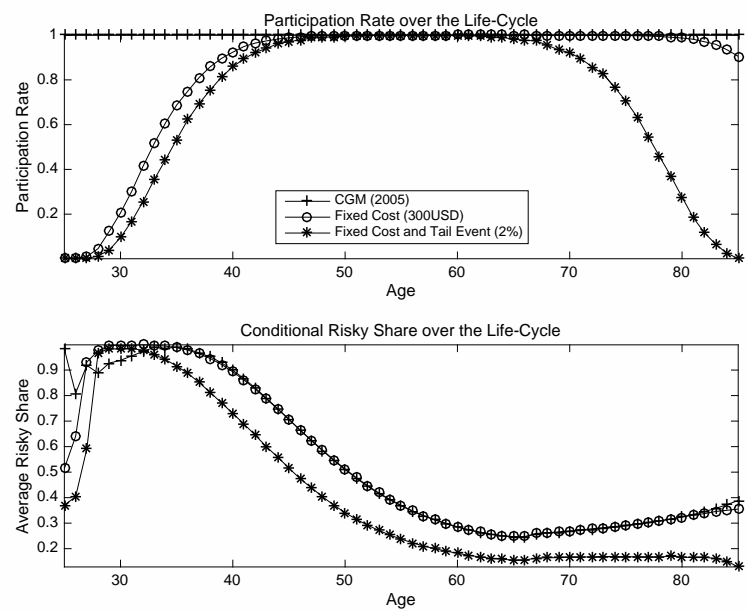

Intensive and Extensive Margin



Financial Wealth

Figure 10. Model simulations. 

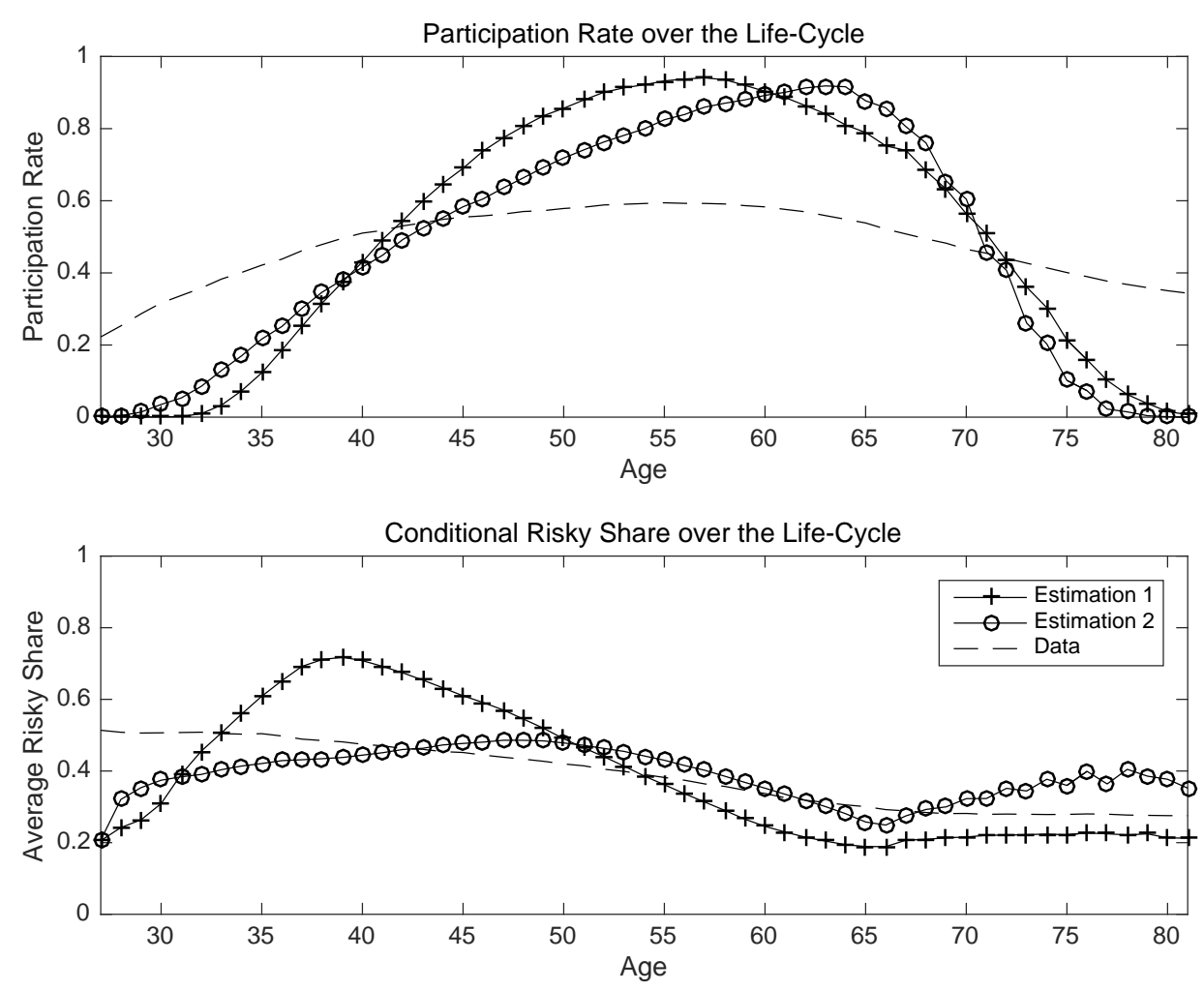

Figure 11. Estimations 1 and 2.
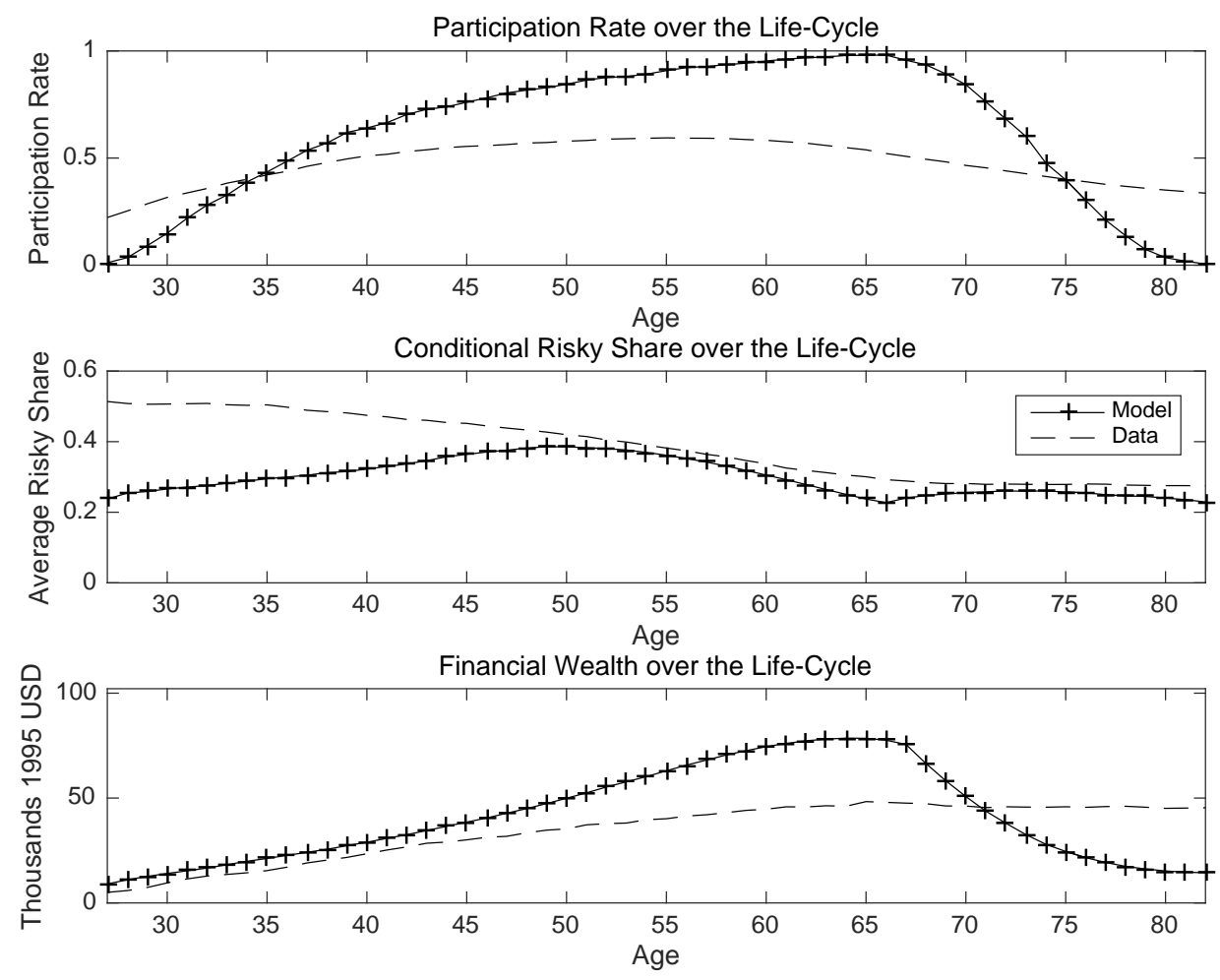

Figure 12. Estimation 3 


\section{Table I \\ Descriptive Statistics, 1995}

This table displays summary statistics for the main sample of married households in the first year of observation, 1995. In addition, the table provides summary statistics for the sample of households that remain in the panel throughout the sample period, which ends in 2009. Where applicable, values are reported in 1995 USD. Education is missing for less than $1 \%$ of the sample.

\begin{tabular}{|c|c|c|c|c|c|c|}
\hline & \multicolumn{3}{|c|}{$\begin{array}{c}\text { Full Sample } \\
\mathrm{N}=164,015\end{array}$} & \multicolumn{3}{|c|}{$\begin{array}{c}\text { Balanced Panel Sample } \\
\text { N=106,369 }\end{array}$} \\
\hline & Mean & Std Dev & Median & Mean & Std Dev & Median \\
\hline \multicolumn{7}{|l|}{ Demographics: } \\
\hline Age husband & 50.88 & 14.14 & 49 & 47.67 & 11.64 & 47 \\
\hline Age wife & 48.12 & 14.01 & 47 & 45.00 & 11.40 & 45 \\
\hline Share less high school education & 0.22 & & & 0.18 & & \\
\hline Share high school education & 0.53 & & & 0.55 & & \\
\hline Share college education & 0.24 & & & 0.27 & & \\
\hline Household size & 3.24 & 1.19 & 3 & 3.44 & 1.17 & 3 \\
\hline \multicolumn{7}{|l|}{ Asset holdings in USD: } \\
\hline Financial wealth & 38,270 & 106,975 & 11,884 & 38,169 & 111,865 & 11,348 \\
\hline Stocks & 12,797 & 91,438 & 0 & 14,386 & 97,230 & 0 \\
\hline Mutual funds & 1,173 & 3,895 & 0 & 1,245 & 3,989 & 0 \\
\hline Safe assets & 24,297 & 37,678 & 9,734 & 22,536 & 35,575 & 9,139 \\
\hline Net worth & 120,354 & 143,051 & 97,543 & 116,213 & 142,199 & 93,318 \\
\hline \multicolumn{7}{|l|}{ Participant share: } \\
\hline Risky assets & 0.33 & 0.47 & 0 & 0.35 & 0.48 & 0 \\
\hline Stocks & 0.23 & 0.42 & 0 & 0.25 & 0.43 & 0 \\
\hline Mutual funds & 0.22 & 0.41 & 0 & 0.23 & 0.42 & 0 \\
\hline Mean share participants: & \multicolumn{3}{|c|}{$\mathrm{N}=54,519$} & \multicolumn{3}{|c|}{$\mathrm{N}=37,770$} \\
\hline Risky assets & 0.32 & 0.30 & 0.20 & 0.33 & 0.31 & 0.22 \\
\hline Stocks & 0.23 & 0.31 & 0.05 & 0.24 & 0.32 & 0.06 \\
\hline Mutual funds & 0.09 & 0.15 & 0.03 & 0.09 & 0.15 & 0.04 \\
\hline Attrition: & \multicolumn{3}{|c|}{$\mathrm{N}=58,863$} & & & \\
\hline Share death & 0.62 & & & & & \\
\hline Share migration & 0.13 & & & & & \\
\hline Share divorce/separation & 0.25 & & & & & \\
\hline Mean yearly attrition rate & 0.030 & 0.000 & & & & \\
\hline Age at exit & 62.63 & 16.83 & & & & \\
\hline
\end{tabular}


Table II

Measures of of Stock Market Entry and Exit

\begin{tabular}{|c|c|}
\hline \multicolumn{2}{|c|}{ Measure 1} \\
\hline Entry: & $\begin{array}{l}\text { The fraction of households that do not hold stocks at age } a \text { that enter } \\
\text { risky asset markets at } a+1 \text {. }\end{array}$ \\
\hline Exit: & $\begin{array}{l}\text { The fraction of households that are stockholders at age } a \text { that exit the } \\
\text { market at age } a+1 \text {. }\end{array}$ \\
\hline \multicolumn{2}{|c|}{ Measure 2} \\
\hline Entry: & $\begin{array}{l}\text { The fraction of households that have never held any stocks up until age } \\
a \text { that enter risky asset markets at } a+1 \text {. }\end{array}$ \\
\hline Exit: & $\begin{array}{l}\text { The fraction of households that are stockholders at age } a \text { that exit the } \\
\text { market at age } a+1 \text { and never reenter the stock market. }\end{array}$ \\
\hline
\end{tabular}

Table III

Heckman Selection Model

This table displays the two estimated Heckman selection models (discussed in Section $[. \mathrm{B}$ ) for asset market participation and the conditional risky share. Lagged total wealth is the sum of financial and human wealth (in 100,000 of 1995 USD), and $\lambda$ is the inverse Mills ratio / nonselection hazard. Coefficients in the selection equation are calculated marginal effects of the underlying probit regression. For presentational purposes, calendar year fixed effects and family size coefficients are reported in Section VI of the Internet Appendix; age coefficients and marginal effects are displayed in Figure 5. Standard errors are in parentheses. ${ }^{*} \mathrm{p}<0.10,{ }^{*} * \mathrm{p}<0.05, * * * \mathrm{p}<0.01$.

\begin{tabular}{lccccc}
\hline & \multicolumn{2}{c}{ Deaton-Paxson } & & \multicolumn{2}{c}{ Cohort Proxy } \\
\cline { 2 - 3 } \cline { 5 - 6 } & $(1)$ & $(2)$ & & $(3)$ & $(4)$ \\
& Participation & Share & & Participation & Share \\
\hline Trend & $0.012^{* * *}$ & $-0.003^{* * *}$ & & & \\
& $(0.001)$ & $(0.001)$ & & $0.361^{* * *}$ & -0.070 \\
Youth stock return & & & & $(0.017)$ & $(0.080)$ \\
& & & & $4.186^{* * *}$ & \\
Lag total wealth & $4.107^{* * *}$ & & & $(0.030)$ & \\
& $(0.148)$ & & & & \\
$\lambda_{\text {iact }}$ & & $-0.186^{* * *}$ & & $-0.186^{* * *}$ & \\
& & $(0.001)$ & & $(0.001)$ & \\
\hline Observations & $1,804,115$ & 886,189 & & $1,804,115$ & 886,189 \\
\hline Joint sign. tests & & & & \\
Year $\chi^{2}(12)$ & $1,575.79^{* * *}$ & $882.70^{* * *}$ & & & \\
Cohort $\chi^{2}(59)$ & $7,644.51^{* * *}$ & $19.17^{* * *}$ & & & \\
\hline
\end{tabular}


Table IV

Parameterization

\begin{tabular}{|c|c|c|c|}
\hline Parameter & & Value & Source \\
\hline Retirement age & $T^{r}$ & 67 & Norwegian Law \\
\hline Risk-free return & $r_{f}$ & 0.0143 & Klovland (2004), \\
\hline Risk premium & $r_{p}$ & 0.0314 & Dimson, Marsh, and Staunton (2008) \\
\hline Stock return std deviation & $\sigma_{r}$ & 0.238 & Ødegaard (2007) \\
\hline Tail event return & $r_{\text {tail }}$ & -0.485 & Table C.II \\
\hline Variance of transitory shocks & $\sigma_{t}^{2}$ & 0.023 & Table A.] \\
\hline Variance of persistent shocks & $\sigma_{p}^{2}$ & 0.012 & Table A.d \\
\hline Replacement ratio & $\phi_{\text {ret }}$ & 0.842 & Table A. \\
\hline Shape of Pareto distribution for $x_{0}$ & $\mu_{x_{0}}$ & 0.4521 & Wealth at age 25 \\
\hline Scale of Pareto distribution for $x_{0}$ & $\sigma_{x_{0}}$ & 5711.7 & Wealth at age 25 \\
\hline
\end{tabular}

Table V

Structural Estimation of Parameters

In Estimations 1 and 2, we target the average participation rate and the average conditional risky share of households between ages 26 and 85. In Estimation 3, we augment the targeted moments with the average financial wealth of households between ages 26 and 85. More details on the estimation can be found in the Internet Appendix. The targeted data moments are those estimated using the Deaton-Paxson methodology in Section 미.

\begin{tabular}{lccc}
\hline & Estimation 1 & Estimation 2 & Estimation 3 \\
\hline Discount factor $(\beta)$ & 0.827 & 0.753 & 0.770 \\
& $(0.03 \mathrm{e}-06)$ & $(0.08 \mathrm{e}-06)$ & $(0.01 \mathrm{e}-06)$ \\
Risk aversion $(\gamma)$ & 14.444 & 11.762 & 11.011 \\
& $(3.05 \mathrm{e}-06)$ & $(1.50 \mathrm{e}-06)$ & $(0.69 \mathrm{e}-06)$ \\
Participation cost $(q)$ & 0.344 & 0.109 & 0.065 \\
& $(0.31 \mathrm{e}-06)$ & $(0.06 \mathrm{e}-06)$ & $(0.05 \mathrm{e}-06)$ \\
Probability of tail event $\left(p_{\text {tail }}\right)$ & - & 0.011 & 0.010 \\
& - & $(0.01 \mathrm{e}-06)$ & $(0.01 \mathrm{e}-06)$ \\
\hline Value of objective function $(L(\hat{\kappa}))$ & 1136.32 & 865.52 & 1406.88 \\
Nr. of targeted moments $(M)$ & 118 & 118 & 177 \\
\hline Wealth to income ratio, age 65 & 3.76 & 1.67 & 1.98 \\
Wealth to income ratio, age $65($ data $)$ & 1.62 & 1.62 & 1.62 \\
\hline
\end{tabular}




\section{Appendix Figures and Tables}
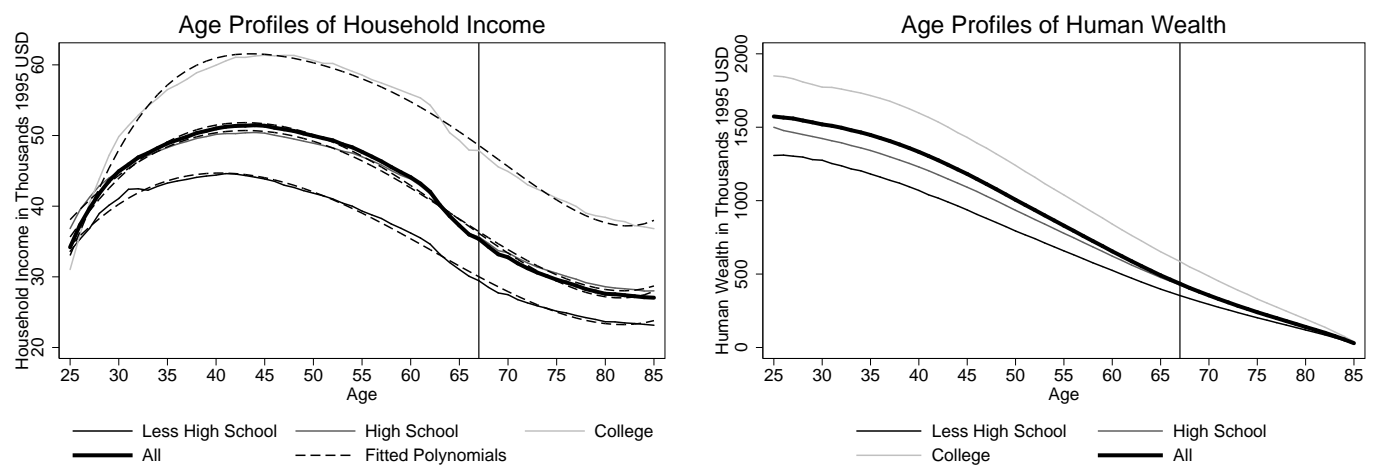

Figure A.1. Life-cycle profiles of labor income and human wealth. The left panel plots the estimated labor income processes by education level and for the full sample, which are estimated applying equation (A]l) on the different subsamples. The right panel displays the life-cycle profiles

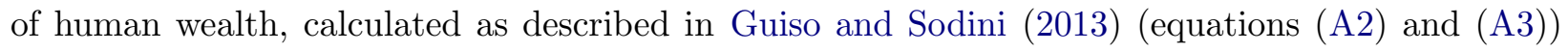
based on the income polynomials in the left panel.

\section{Table A.I}

Income Variance Decomposition and Correlation with Stock Returns

This table reports estimates of the variance of permanent and transitory labor income shocks. The estimation is based on the error terms from estimating the labor income process in Figure A.T. The procedure is based on the method in Carroll and Samwick (1997), which is also used in Cocco, Gomes, and Maenhout (2005). t-values are in parentheses.

\begin{tabular}{lcccc}
\hline & $<$ High School & High School & College & All \\
\hline Transitory & 0.026 & 0.015 & 0.029 & 0.023 \\
& $(9.97)$ & $(6.76)$ & $(11.89)$ & $(16.5)$ \\
Permanent & 0.013 & 0.011 & 0.011 & 0.012 \\
& $(17.44)$ & $(19.12)$ & $(17.73)$ & $(31.11)$ \\
Stock market & & & & \\
& 0.017 & 0.045 & 0.005 & 0.008 \\
& $(0.48)$ & $(0.34)$ & $(0.75)$ & $(0.50)$ \\
\hline
\end{tabular}


Table A.II

\section{Labor Income Process: Age Polynomials}

The table shows the coefficients of the fifth-order polynomial that approximates labor income as a function of age for various population groups.

\begin{tabular}{lcccc}
\hline & $<$ High School & High School & College & All \\
\hline Age & 0.0418 & 0.0375 & 0.112 & 0.0572 \\
Age $^{2} / 10$ & -0.0231 & -0.0176 & -0.0689 & -0.0308 \\
Age $^{3} / 100$ & 0.00587 & 0.00454 & 0.0212 & 0.00888 \\
Age $^{4} / 1000$ & -0.101 & -0.0906 & -0.337 & -0.161 \\
Age $^{5} / 10000$ & 0.0749 & 0.0735 & 0.208 & 0.117 \\
Constant & 3.576 & 3.657 & 3.415 & 3.566 \\
\hline Observations & 61 & 61 & 61 & 61 \\
$r^{2}$ & 0.995 & 0.996 & 0.988 & 0.995 \\
\hline
\end{tabular}

Table C.I

Large Stock Market Drops Experienced by Households

The table displays the distribution of the number of large stock market drops (in the upper panel drops of more than $25 \%$ in a year, and in the lower panel drops of more than 30\%) experienced by the households in the sample for various age groups: above the age of 18 , between ages 18 and 36, between ages 18 and 42, and between ages 18 and 55 .

\begin{tabular}{|c|c|c|c|c|}
\hline & \multicolumn{4}{|c|}{ Experience of medium/large drops $\geqq 25 \%$} \\
\hline Number of & Total & Age Bracket & Age Bracket & Age Bracket \\
\hline Drops & Life-Cycle & $18-36$ & $18-42$ & $18-55$ \\
\hline 0 & 1.52 & 39.97 & 24.89 & 5.45 \\
\hline 1 & 2.28 & 18.85 & 8.77 & 6.22 \\
\hline 2 & 8.90 & 41.01 & 63.25 & 39.21 \\
\hline 3 & 22.04 & 0.17 & 3.09 & 24.03 \\
\hline 4 & 17.49 & & & 19.46 \\
\hline 5 & 47.77 & & & 5.63 \\
\hline Mean & 3.9 & 1.0 & 1.4 & 2.66 \\
\hline \multirow[t]{2}{*}{ Median } & 4 & 1 & 2 & 3 \\
\hline & \multicolumn{4}{|c|}{ Experience of large drops $\geqq 30 \%$} \\
\hline Number of & Total & Age Bracket & Age Bracket & Age Bracket \\
\hline Drops & Life-Cycle & $18-36$ & $18-42$ & $18-55$ \\
\hline 0 & 4.37 & 53.36 & 35.40 & 8.36 \\
\hline 1 & 17.99 & 46.47 & 61.52 & 54.42 \\
\hline 2 & 29.88 & 0.17 & 3.09 & 31.59 \\
\hline 3 & 47.77 & & & 5.63 \\
\hline Mean & 2.2 & 0.5 & 0.7 & 1.3 \\
\hline Median & 2 & 0 & 1 & 1 \\
\hline
\end{tabular}


Table C.II

Net Returns on Risky Assets in 2008

The table gives summary statistics of the cross-sectional distribution of net returns on households' risky asset portfolios in 2008.

\begin{tabular}{lc}
\hline Percentile & Net Return \\
\hline 1st & $-70 \%$ \\
5 th & $-58.6 \%$ \\
10 th & $-56.4 \%$ \\
25 th & $-55.3 \%$ \\
50 th & $-47.8 \%$ \\
75 th & $-47.0 \%$ \\
90 th & $-46.7 \%$ \\
95 th & $-41.0 \%$ \\
99 th & $-29.8 \%$ \\
\hline Mean & $-48.5 \%$ \\
Range & $-40.2 \%$ \\
Std Dev & $6.0 \%$ \\
\hline
\end{tabular}

